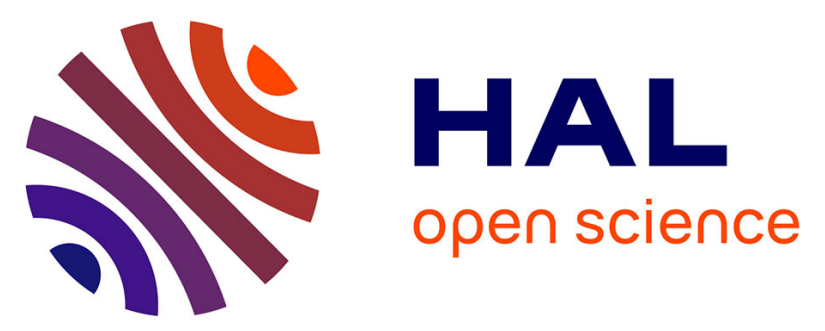

\title{
Effect of nanosilica additive particles on both friction and wear performance of mild steel/CuSn/SnBi multimaterial system
}

H. Ait-Sadi, L. Hemmouche, L. Hattali, M. Britah, Alain Iost, N. Mesrati

\section{- To cite this version:}

H. Ait-Sadi, L. Hemmouche, L. Hattali, M. Britah, Alain Iost, et al.. Effect of nanosilica additive particles on both friction and wear performance of mild steel/CuSn/SnBi multimaterial system. Tribology International, 2015, 90, pp.372-385. 10.1016/j.triboint.2015.04.034 . hal-01169344v2

\section{HAL Id: hal-01169344 \\ https://hal.science/hal-01169344v2}

Submitted on 14 Feb 2017

HAL is a multi-disciplinary open access archive for the deposit and dissemination of scientific research documents, whether they are published or not. The documents may come from teaching and research institutions in France or abroad, or from public or private research centers.
L'archive ouverte pluridisciplinaire HAL, est destinée au dépôt et à la diffusion de documents scientifiques de niveau recherche, publiés ou non, émanant des établissements d'enseignement et de recherche français ou étrangers, des laboratoires publics ou privés. 


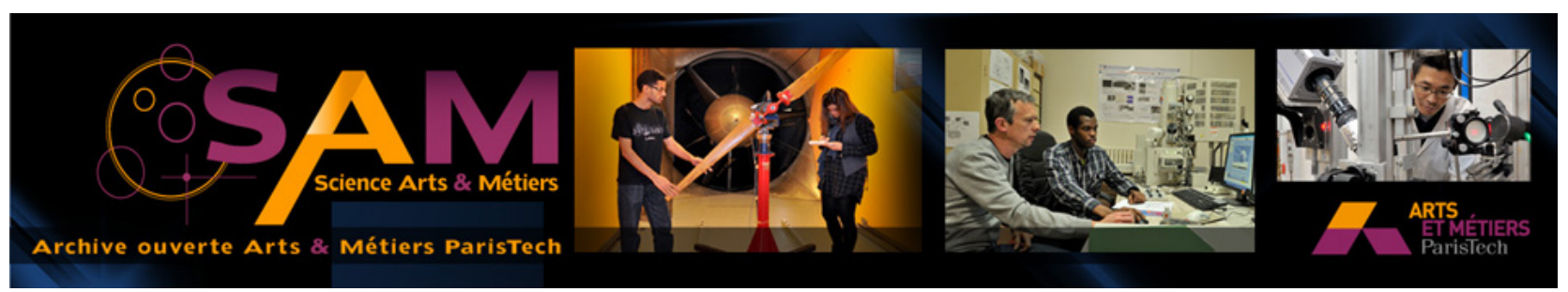

Science Arts \& Métiers (SAM)

is an open access repository that collects the work of Arts et Métiers ParisTech researchers and makes it freely available over the web where possible.

This is an author-deposited version published in: http://sam.ensam.eu

Handle ID: .http://hdl.handle.net/10985/9655

\section{To cite this version :}

H. AIT-SADI, L. HEMMOUCHE, L. HATTALI, M. BRITAH, Alain IOST, N. MESRATI - Effect of nanosilica additive particles on both friction and wear performance of mild steel/CuSn/SnBi multimaterial system - Tribology International - Vol. 90, p.372-385 - 2015 


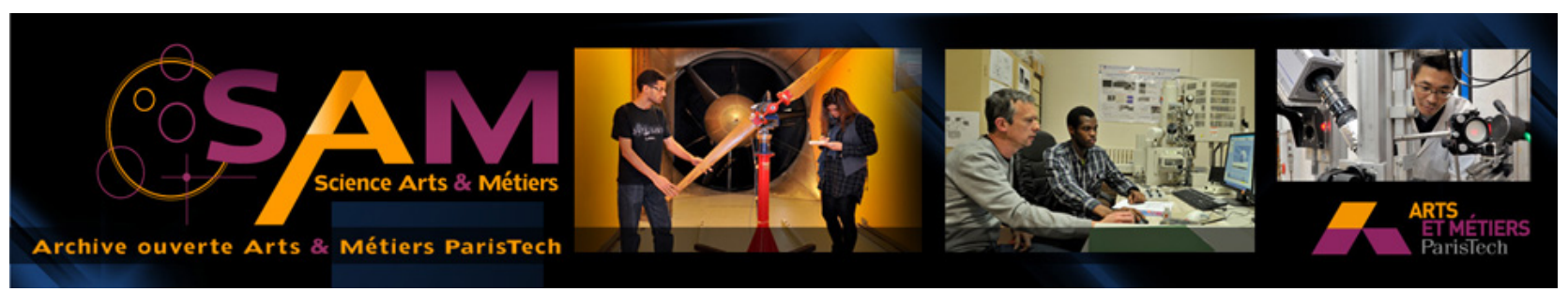

Science Arts \& Métiers (SAM)

is an open access repository that collects the work of Arts et Métiers ParisTech researchers and makes it freely available over the web where possible.

This is an author-deposited version published in: http://sam.ensam.eu

Handle ID: .http://hdl.handle.net/10985/9655

\section{To cite this version :}

H. AIT-SADI, L. HEMMOUCHE, L. HATTALI, M. BRITAH, Alain IOST, N. MESRATI - Effect of nanosilica additive particles on both friction and wear performance of mild steel/CuSn/SnBi multimaterial system - Tribology International - Vol. 90, p.372-385 - 2015 


\title{
Effect of nanosilica additive particles on both friction and wear performance of mild steel/CuSn/SnBi multimaterial system
}

\author{
H. Ait-Sadi ${ }^{\text {a,*, }}$, L. Hemmouche ${ }^{\text {a }}$, L. Hattali ${ }^{\text {b }}$, M. Britah ${ }^{\text {a }}$, A. Iost ${ }^{c}$, N. Mesrati ${ }^{\mathrm{d}}$ \\ a Laboratoire Génie des Matériaux, Ecole Militaire Polytechnique, BP17 Bordj El Bahri, Algeria \\ ${ }^{\mathrm{b}}$ Univ Paris-Sud, CNRS, UMR 7608, Lab FAST, Bat 502, Campus Univ, F-91405 Orsay, France \\ c LMSMP, ENSAM 8, Boulevard Louis XIV, 59046 Lille, France \\ d LSGM, ENP, 10 Avenue Hassan Badi, El Harrach, Algeria
}

Keywords:

Copper composite

$\mathrm{SiO}_{2}$ nanoparticles

Powder metallurgy

Friction/wear

\begin{abstract}
A B S T R A C T
This paper presents an experimental study of the tribological behaviour of a multimaterial system using conventional powder metallurgy process with $\mathrm{SiO}_{2}$ nanoparticles. Four configurations were studied with and without $\mathrm{SiO}_{2}$. The tribological properties of the sintered materials were analysed by wear experiments at lubricated conditions on a ball disc wear test rig. The results are compared with those of conventional material for journal bearing. These show less variation of the friction coefficient and less wear rate for the materials with $\mathrm{SiO}_{2}$ compared to the ones without $\mathrm{SiO}_{2}$ and to those of the reference material. The dominant wear mechanism is adhesive wear, accompanied by mild abrasive wear.
\end{abstract}

\section{Introduction}

Powder metallurgy (PM) is one of the most popular solid state methods used in production of metal composites [1-2]. In PM, the ultimate fabrication procedures of these composites have been well established and consist of mechanical milling, compacting, sintering and plastic deformation. The mechanical milling is based on a high energy ball milling process where a mixture of powders (of different metals or alloys/compounds) is milled together due to high energy collisions with the balls [3-6]. The compacting process is a method of creating a single metal or a non-metal layer or a composite material as required. The newly produced material needs to have a solid mass of desired shape with an adequate strength in order to cope with the sintering process without breakage or damage. The sintering process involves a thermal treatment of bonding particles together into a coherent, predominantly solid structure via mass transport events that occur largely at the atomic level. The bonding leads to improve the strength and to lower the system energy. Technical and economical advantages of the powder metallurgy have led [7] (i) to produce a wide range of new materials with unique properties from components that have different melting temperatures or show liquid immiscibility, (ii) to control the grain size by varying the reduction ratio of the initial components, and (iii) to develop

\footnotetext{
* Corresponding author.

E-mail address: hassibaaitsadi@yahoo.fr (H. Ait-Sadi).
}

composites by combining a high-strength components. This has resulted in a sintered method which is one of the most important technological methods in PM [8-12]. Since this method makes it possible to combine in one material the most valuable properties of the original substances, where individually, they do not exhibit the whole set of requirements, therefore enhancing the performance characteristics of antifriction materials. The general principle underlying the creation of antifriction powder materials is to form highly heterogeneous structures that have two components with strictly different functions. The first component is the loadbearing matrix that ensures the necessary strength and the loadcarrying capacity. The second one is the antifriction component that acts as a solid lubricant, reduces the coefficient of friction and increases the wear resistance [13-14]. In fact, the sintered methods involve the analysis of the interaction of its components during the production process because the structure and phase transformations at the interface produce the general structure.

It is well known that the copper-based bronze has a long history of development and applications in the automobile and engineering industries as bearing materials with or without overlay. Copperbased bronze is particularly used in the friction devices of various mechanism and applications due to their heat conductivity, wear resistance and stable chemical properties $[3,12]$. The copper-lead alloy has sufficient fatigue strength with good seizure resistance to be used with an overlay as an engine bearing material.

However, lead is widely perceived to have an inherent toxicity that causes deleterious and cumulative toxic effects on the environment [15-20]. In order to meet the requirements of future 
possible applications, it is important to improve the existing and to develop new lead free materials with enhanced tribological properties [21]. Bismuth is another material with properties similar to those of lead. It is, however, nontoxic and is suitable for replacing lead as a seizure resistant material both in the overlay and in the lining materials [22-25]. The extensive use of nano-structured materials in the automotive and the engineering industries has increased due to their high strength, high thermal stabilities and high wear resistance in comparison with monolithic alloys [2-3]. These advantages are in addition to the availability of inexpensive reinforcements, cost effective processing methods and the unique combination of improvement in mechanical, tribological and thermal properties.

Some researchers [26-31] have summarized the role of addition of $\mathrm{SiO}_{2}$ nanoparticles on the tribological behaviour of friction materials (FMs). Their results indicate that the $\mathrm{SiO}_{2}$ nanoparticles were believed to be the ideal solution that exhibits remarkable wear resisting and friction reducing behaviours. Some publications [3235 ] investigated the structure and the tribological properties of $\mathrm{SiO}_{2}$ nanoparticles additive in many organic solvents such as diesel oil, liquid paraffin and on the zinc phosphating of carbon steel. These nanoparticles show superior dispersivity and better corrosion resistance. They were imbedded into the micro-cracks on the surface of the friction couples to prevent the cracks from further expanding and to increase the anti-wear ability. Shang et al. [36] examined the tribological behaviour of $\mathrm{Cu}-\mathrm{SiO}_{2}$ composite. They concluded that the main formation mechanism of the laminar-structured tribolayer is the grain boundary sliding. Despite the large number of reports on the performance of the copper-based alloy and copper reinforced composite, the quantity and the content of the works published in this area do not seem sufficient to draw a plausible conclusion about the overall tribological behaviour and the wear mechanism of copper-based alloy/nanosilica prepared by sintering process.

The aim of this study is to evaluate the effect of an addition of nanosilica $\mathrm{SiO}_{2}$ on the tribological and the mechanical behaviour of some copper-based materials. In this paper, we present our experiments and results on the friction properties using the ball on disc technique and the changes in microstructure correlated with nano$\mathrm{SiO}_{2}$ and the wear mechanisms.The wear rate and the friction coefficient are the two parameters used in the comparative study between these alloys and corresponding conventional material.

\section{Materials and experimental procedures}

\subsection{Materials}

Electrolytic and spheroidal copper powder (Cu) (average grain size $\sim 50 \mu \mathrm{m}$; $99.98 \%$ purity), pulverised spheroidal tin powder
(Sn) (average grain size $\sim 60 \mu \mathrm{m}$; 99.99\% purity), pure spherical bismuth powder (Bi) (average grain size $<150 \mu \mathrm{m}$; 99.98\% purity), and spheroidal $\mathrm{SiO}_{2}$ nano silicate particles (average grain size $\sim 30 \mathrm{~nm}$ ) were used as multilayers coatings. Mild steel discs of $30 \mathrm{~mm}$ diameter and $3 \mathrm{~mm}$ thickness was used as the substrate for these coatings. Four multilayer composition labelled $\mathrm{S}_{1}$ (Mild Steel/CuSn/SnBi), $\mathrm{S}_{2}$ (Mild Steel/CuSn/SnBiSiO${ }_{2}$ ), $\mathrm{S}_{3}$ (Mild Steel/ $\left.\mathrm{CuSiO}_{2} / \mathrm{SnBi}\right)$, and $\mathrm{S}_{4}\left(\mathrm{Mild} \mathrm{Steel} / \mathrm{CuSiO}_{2} / \mathrm{SnBiSiO}_{2}\right)$ were built and tested.

The composites materials were manufactured by using PM technology which consisted of compacting and sintering the powder at high temperature. The material details of the linings are listed in table 1 . Square samples of $20 \mathrm{~mm}$ side length were cut from conventional bearing bronze (SAE 49P) and considered as a reference. The chemical composition of the conventional bearing bronze and the above samples are shown in Table 1.

Prior to sintering, the $\mathrm{Cu}-5 \mathrm{wt} \% \mathrm{Sn}$ and $\mathrm{Cu}-1 \mathrm{wt} \% \mathrm{SiO}_{2}$ powders were mechanically mixed in a revolving crushing jar at a speed of 60 revolutions/min during $24 \mathrm{~h}$. The morphology of milled Cu$5 \mathrm{wt} \% \mathrm{Sn}$ has an irregular shape with average particles size of about 30-95 $\mu \mathrm{m}$ while milled $\mathrm{Cu} 1 \% \mathrm{wt} \% \mathrm{SiO}_{2}$ has spheroidal shape morphology with average size of about $40-50 \mu \mathrm{m}$. This mixture was deposited on the copper electroplated steel backing discs of $30 \mathrm{~mm}$ diameter and $3 \mathrm{~mm}$ thickness.

The discs were used as substrates and then compacted using a hydraulic press at $250 \mathrm{MPa}$ pressure. Most of sintering process was done in hydrogen and the first sintering layer was formed at $900{ }^{\circ} \mathrm{C}$ over an hour, followed by the second layer using the $\mathrm{SnBi}$ $40 \mathrm{wt} \%$ mixed powder and/or SnBi mixed powder with addition of $1 \mathrm{wt} \% \mathrm{SiO}_{2}$ nanoparticles (Fig. 1). The second sintering temperature was at $550{ }^{\circ} \mathrm{C}$ for one hour in hydrogen. These sintering temperatures were chosen to maintain the optimum mechanical properties and the minimal porosity of the composite. The porosity of the studied specimens was about $8 \%$ after the sintering. The microstructure of each configuration was analysed by Optical

Table 1

The material composition details.

\begin{tabular}{|c|c|c|c|}
\hline Material & $\begin{array}{l}\text { Steel, } \\
\mathrm{ep}^{*}: 3 \mathrm{~mm}\end{array}$ & 1st Layer, ep: $0.3 \mathrm{~mm}$ & 2nd Layer, ep: $0.1 \mathrm{~mm}$ \\
\hline$S_{1}$ & Mild steel & $\mathrm{Cu} 5$ wt\% Sn & Sn 40 wt \%Bi \\
\hline $\mathrm{S}_{2}$ & Mild steel & Cu 5 wt\% Sn & $\begin{array}{l}\text { Sn } 40 \text { wt\% Bi with } 1 \text { wt\% } \\
\mathrm{SiO}_{2}\end{array}$ \\
\hline $\mathrm{S}_{3}$ & Mild steel & $\mathrm{Cu} 1 \mathrm{wt} \% \mathrm{SiO}_{2}$ & Sn 40 wt.\%Bi \\
\hline $\mathrm{S}_{4}$ & Mild steel & $\mathrm{Cu} 1 \mathrm{wt} \% \mathrm{SiO}_{2}$ & $\begin{array}{l}\text { Sn } 40 \text { wt.\% Bi with } 1 \text { wt.\% } \\
\mathrm{SiO}_{2}\end{array}$ \\
\hline SAE 49P & Mild steel & $\begin{array}{l}\text { Cu } 23 \text { wt\% Pb } 1 \text { wt\% } \\
\text { Sn }\end{array}$ & \\
\hline
\end{tabular}
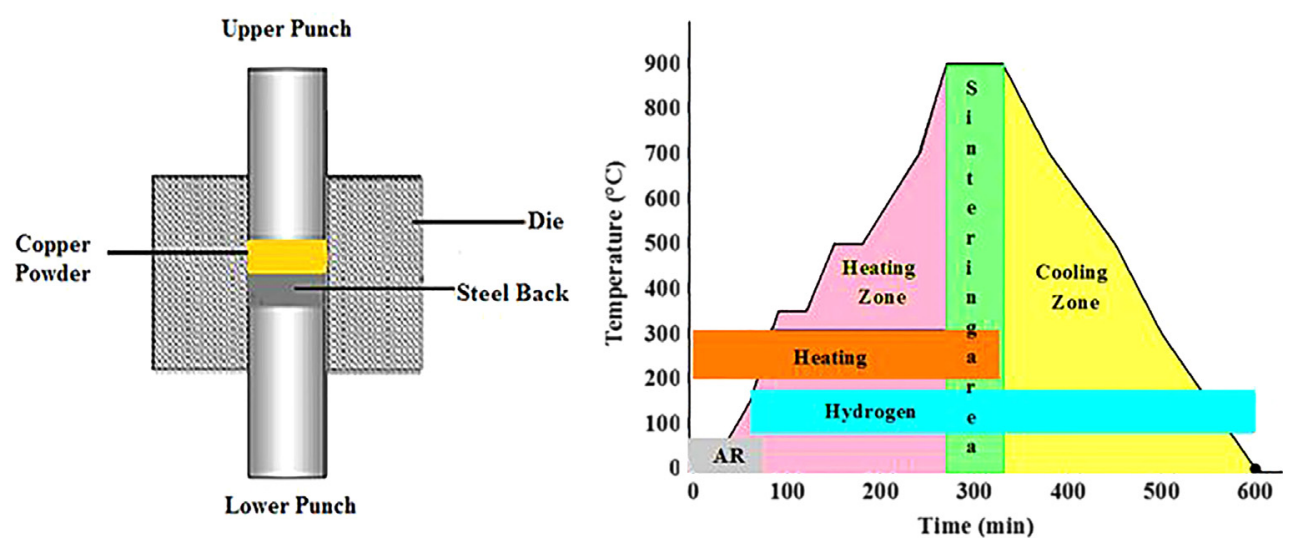

Fig. 1. Schematic drawing of the sintering process, and thermal cycle of first layer. 

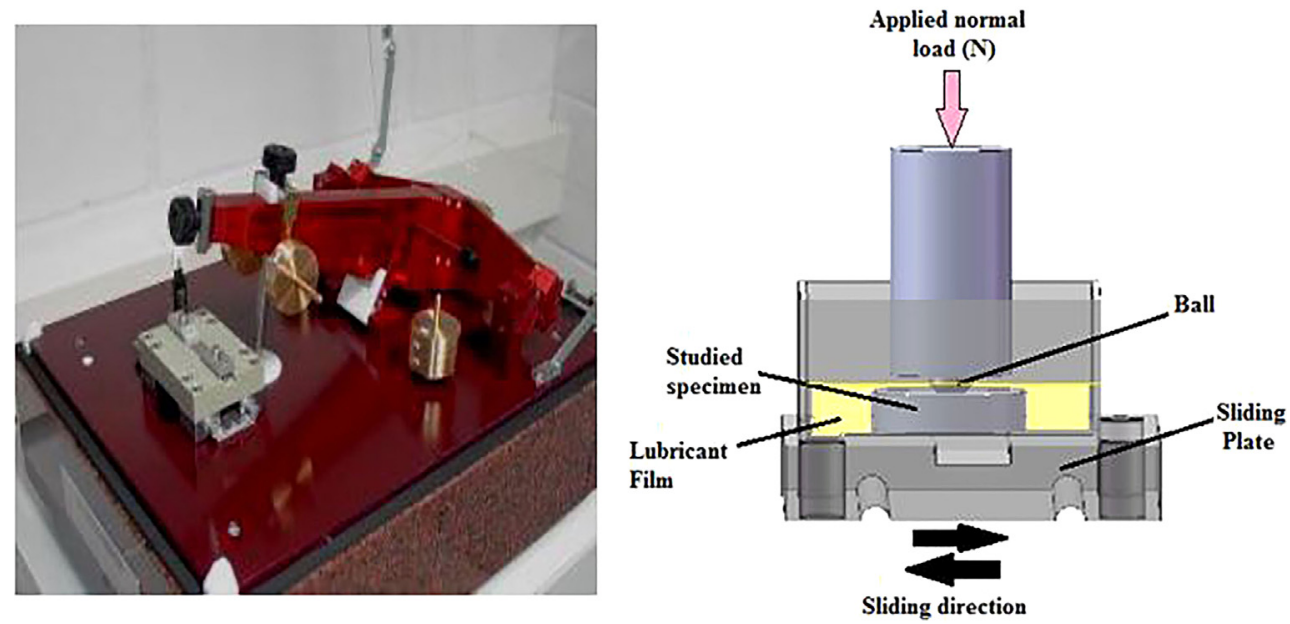

Fig. 2. Tribometer illustration and its process.

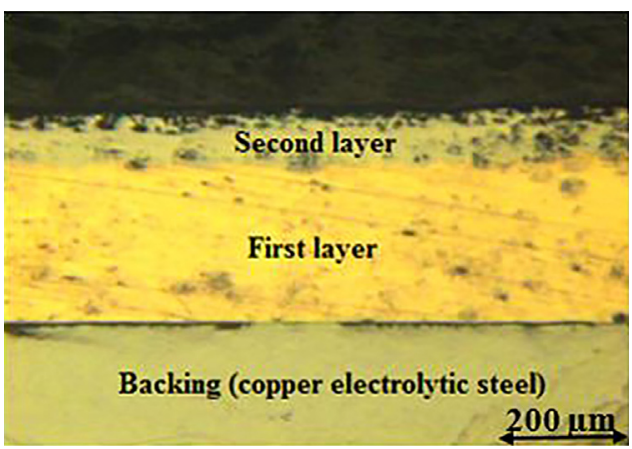

Fig. 3. Construction of specimen.

microscopy and Scanning Electronic Microscope (SEM) (FEI, Quanta 600).

\subsection{Friction and wear tests}

The tribological tests were performed under laboratory conditions (temperature, $T=25{ }^{\circ} \mathrm{C}$, humidity $~ 50 \%$ ) using the ball on the disc test wearing-“Tribotechnic standard ISO 7148" (Fig. 2). The disc samples of the deposited films were sliding against the ball of $6 \mathrm{~mm}$ diameter made of steel 100C6. The wear tests were carried out under a lubricant atmosphere with the normal loads of 10 and $12 \mathrm{~N}$. The specimens' sliding speeds were 15 and $30 \mathrm{~mm} / \mathrm{s}$ over a constantly maintained sliding distance of $4000 \mathrm{~m}$ for each sample that corresponded to a time scale of 38 and $74 \mathrm{~h}$. The selected lubricant was the commercial oil MA5 supplied by a manufacturer group Peugeot-Citroen PSA. The friction coefficient was monitored in real time during the tests. The resulting material loss due to the wear and parameters of rugosity before and after wear tests were measured using WYKO NT9300 non-contact optical profiler (Veeco) interfaced with Vision ${ }^{\circledR} 32$ software under sealing interferometry according to two processes PSI "Phase Shift interference" (Rt $<150 \mathrm{Nm}$ ) and VSI "Vertical Shift Interference" (Rt $>150 \mathrm{Nm}$ ). In this work, VSI was used. The results were obtained for the different specimens that were run at different loads and speeds. Scanning Electronic Microscope (SEM) (FEI, Quanta 600) characterized the worn surface after each test.

\section{Results and discussion}

\subsection{Microstructures}

Fig. 3 illustrates the construction of the multilayered specimens under investigation. Fig. 4a shows the optical micrograph of the conventional copper-based reference material layer. This optical micrograph shows that microstructure of SAE contains a dendritic structure with large globules of lead (dark) and copper dendrites (light). Fig. 4b shows the first manufactured deposited layers that depicts a similar microstructure with a uniform and fine dispersion of the copper matrix. The light areas are the copper-rich matrix phase of the primary and monotectic constituents and the dark areas are the thin-rich phase. Fig. 4c shows the SEM micrograph of the $\mathrm{CuSiO}_{2}$ first layer. It can be noticed that the aggregates of $\mathrm{SiO}_{2}$ nanoparticles (area indicated by "A" in Fig. 4c) are unevenly distributed in the copper matrix. Fig. 4d and e shows the SEM micrographs of the SnBi second layers with and without the addition of nanoparticles respectively; the microstructure of binary layer consists of tin rich phase $\alpha$, a dendrites surrounded by the dark areas which is the Bismuth rich phase.

\subsection{Friction performance}

The variation of sliding dependences of the friction coefficient (COF) under different conditions for each material is shown in Fig. 5. The behaviour during the early stages of the sliding varies considerably. It can be seen from the curves that the initial friction coefficients have increased rapidly with the sliding distance to a relatively steady value after approximately $100 \mathrm{~m}$. This increase in COF corresponds to an increase in apparent contact area. In the first cycle, there is a line contact between the ball and the disc. However, the ball gradually adopts the profile of the disc as the wear occurs. It results in an increase of the apparent contact area until the contact occurs across the full diameter of the ball due to a certain conformation of the sliding surfaces. Fig. 5a reveals the variation of COF of $S_{1}$, where it can be noted that, at the start, the fluctuations of COF are the smallest in all conditions and its value range between 0.08 and 0.12 . As the sliding distance increases, the value of COF fluctuates between the minimum values of 0.07 to 0.11. The initial value of COF decreases in all conditions, this decrease is then followed by broad gorge, after which COF reaches the steady value ranging from 0.09 to 0.11 . Ultimately, the highest 

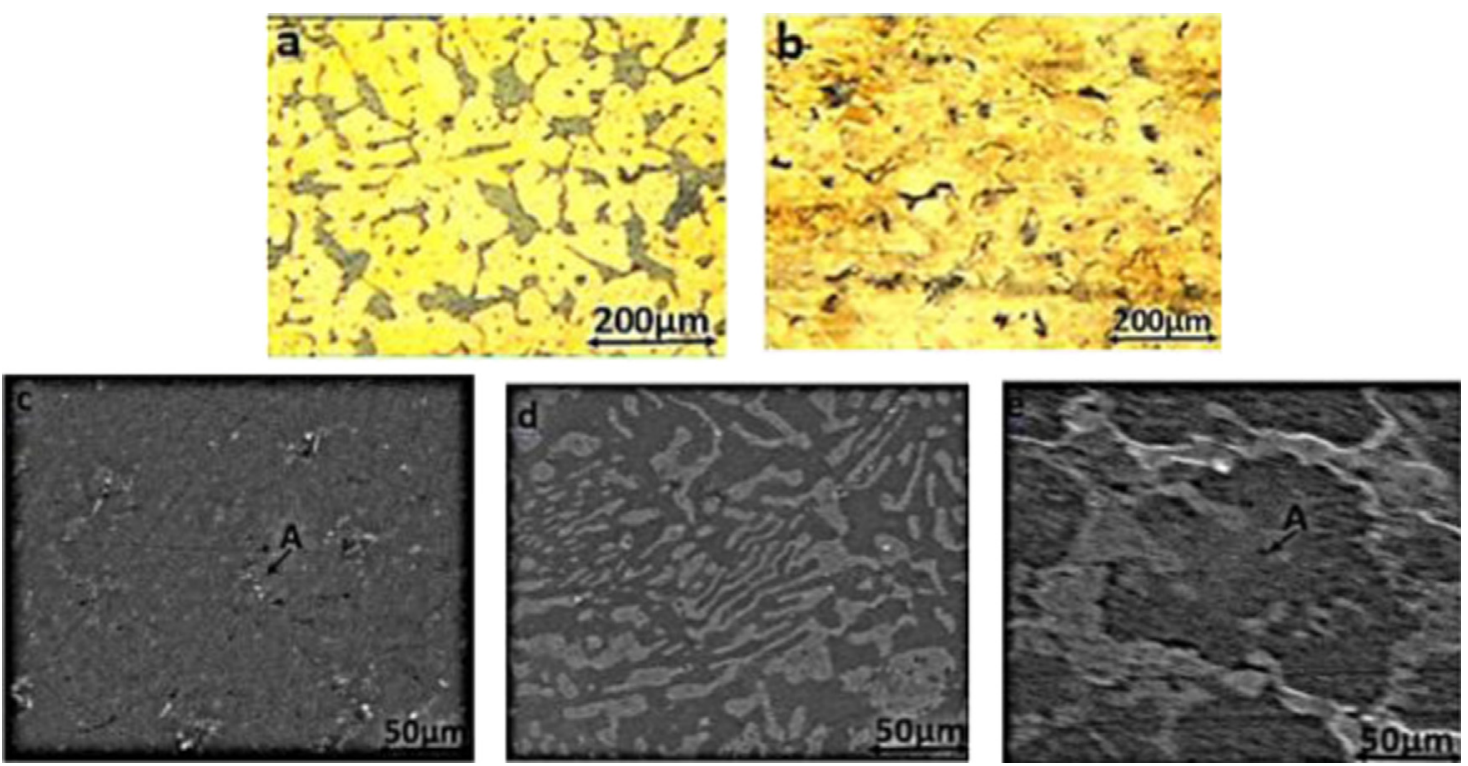

Fig. 4. Microstructures of the materials used: (a) optical micrograph of SAE49P, (b) optical micrograph of Cu-5 wt\% Sn, (c) SEM micrograph of Cu- $1 \%$ nanoSiO 2 , (d)SEM micrograph of $\mathrm{Sn} 40 \mathrm{wt} \% \mathrm{Bi}$, (e) SEM micrograph of $\mathrm{Sn} 40 \mathrm{wt} \% \mathrm{Bi}$ with $\mathrm{SiO}_{2}$ nanoparticles addition.
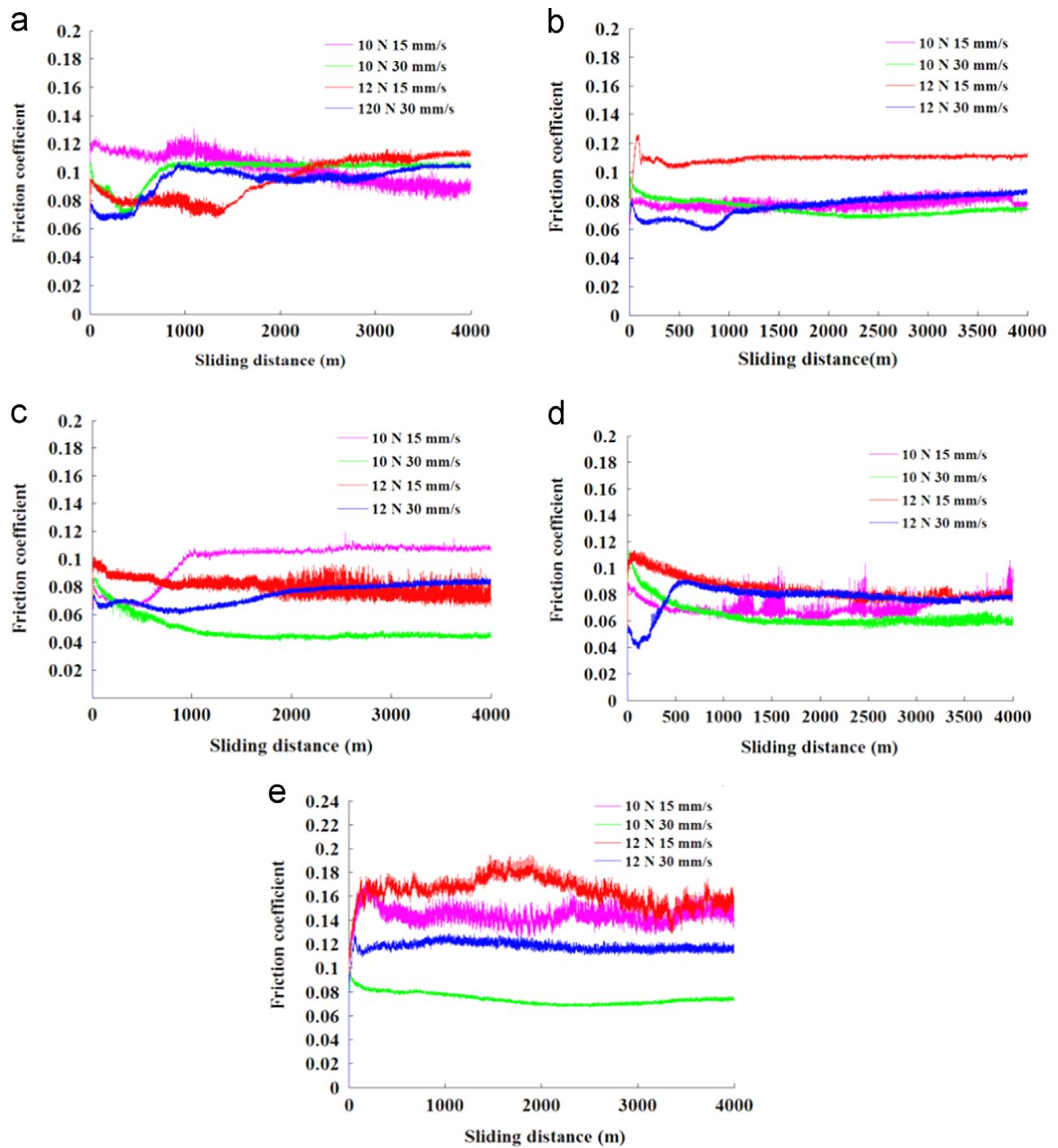

Fig. 5. Evolution of friction coefficient of: (a) $S_{1}$; (b) $S_{2}$; (c) $S_{3}$; (d) $S_{4}$; (e) SAE 49. 

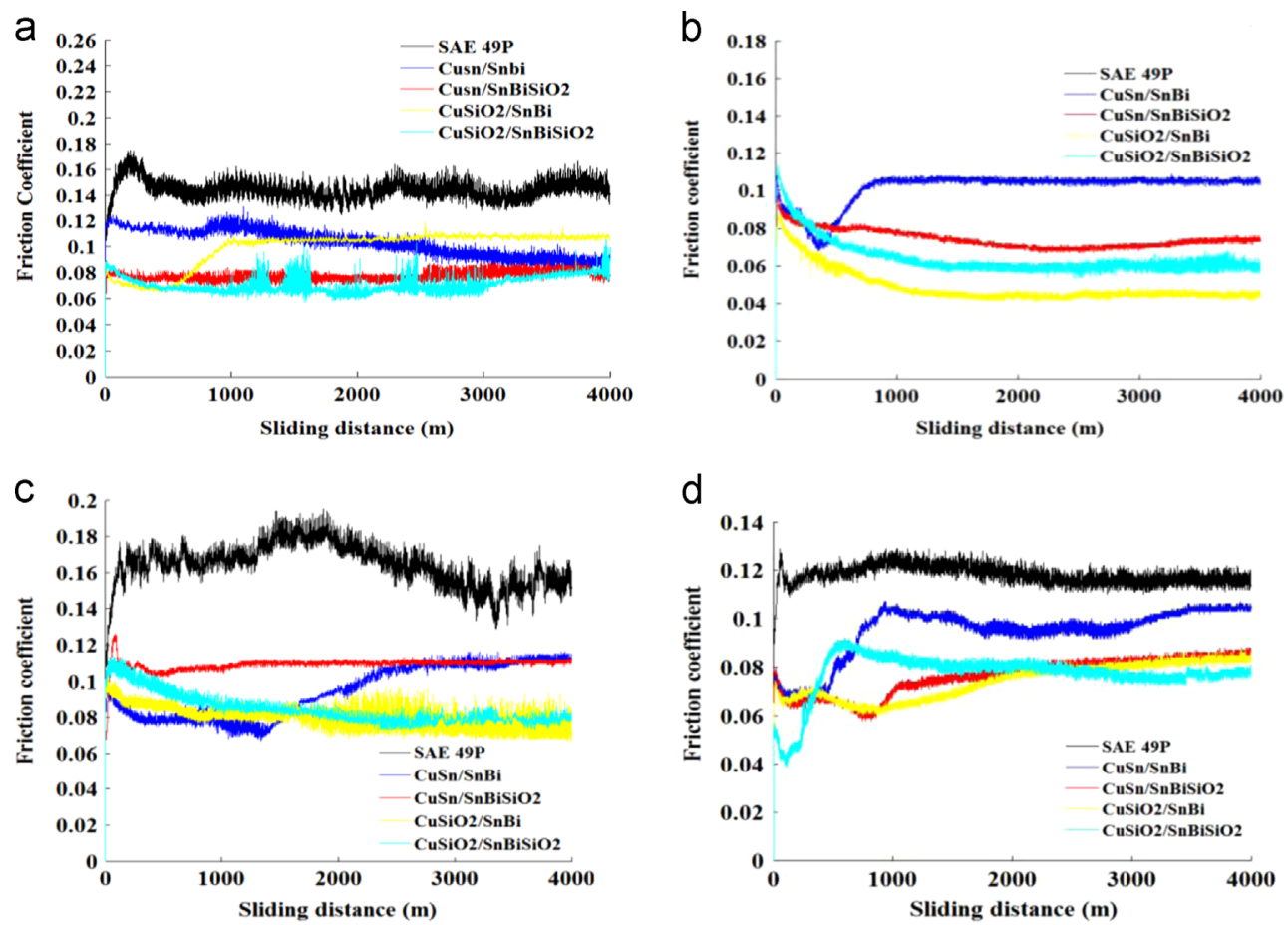

Fig. 6. Evolution of friction coefficient at: (a) $10 \mathrm{~N} 15 \mathrm{~mm} / \mathrm{s}$, (b) $10 \mathrm{~N} 30 \mathrm{~mm} / \mathrm{s}$, (c) $12 \mathrm{~N} 15 \mathrm{~mm} / \mathrm{s}$, (d) $12 \mathrm{~N} 30 \mathrm{~mm} / \mathrm{s}$.

COF of 0.11 is observed for $S_{1}$ at $12 \mathrm{~N} 15 \mathrm{~mm} / \mathrm{s}$ and the lowest COF of 0.08 is obtained at $10 \mathrm{~N} 15 \mathrm{~mm} / \mathrm{s}$ and $12 \mathrm{~N} 30 \mathrm{~mm} / \mathrm{s}$.

Fig. 5b shows different system behaviour, in $\mathrm{S}_{2}$ materials that illustrates smooth friction coefficient characteristics. In addition, it is evident that the friction curves for $10 \mathrm{~N} 15 \mathrm{~mm} / \mathrm{s}$ become relatively stable as the sliding distance increases and COF reaches a stable value of 0.08 . At the end of the running-in process, COF for $10 \mathrm{~N} 30 \mathrm{~mm} / \mathrm{s}$ reaches a stable value $(0.074)$ and it does not change significantly. The COF for $12 \mathrm{~N} 15 \mathrm{~mm} / \mathrm{s}$ decreases to 0.105 at the initial running distance; after which, the friction coefficient reaches a stable value of 0.11 . Furthermore, the curve behaviour for $12 \mathrm{~N} 30 \mathrm{~mm} / \mathrm{s}$ includes a decrease from the initial value of friction, followed by a broad peak (0.06-0.07), after which COF reaches the steady value (0.08). Fig. $5 \mathrm{c}$ shows the variation of COF, of $\mathrm{S}_{3}$ under all conditions. This variation has a poor initial reduction in the first $500 \mathrm{~m}$ of the test, while the surface gets adapted to the working mode with the exception of the evolution of friction coefficient curve under parameters of $10 \mathrm{~N} 30 \mathrm{~mm} / \mathrm{s}$. This curve depicts a quick initial reduction followed by a steady state at 0.045 . The friction coefficient increases to 0.105 for $10 \mathrm{~N}$ $15 \mathrm{~mm} / \mathrm{s}$, after which, COF remains stable until the end of the test. In summary, the highest COF (0.105) occurs for $10 \mathrm{~N} 15 \mathrm{~mm} / \mathrm{s}$, whereas the lowest COF (0.045) occurs for $10 \mathrm{~N} 30 \mathrm{~mm} / \mathrm{s}$. Fig. $5 \mathrm{~d}$ shows that, after a short running-in process, COF of $\mathrm{S}_{4}$ gradually decreases with the sliding distance and reaches a steady state for most cases, with a narrow range of fluctuations in the case of $10 \mathrm{~N}$ $15 \mathrm{~mm} / \mathrm{s}$, with the exception of COF for $12 \mathrm{~N} 30 \mathrm{~mm} / \mathrm{s}$, where it decreases far quicker and forms a broad peak.to reach a steady state value.

In brief, the highest COF (0.08) occurs for $10 \mathrm{~N} 15 \mathrm{~mm} / \mathrm{s}, 12 \mathrm{~N}$ $15 \mathrm{~mm} / \mathrm{s}$ and $12 \mathrm{~N} 30 \mathrm{~mm} / \mathrm{s}$, whereas the lowest COF (0.06) occurs for $10 \mathrm{~N} 30 \mathrm{~mm} / \mathrm{s}$. Fig. 5e depicts the changes of the friction coefficient with the sliding distance of the conventional material (SAE 49P). At the beginning, COF increases rapidly with the sliding distance in a short period of time, and reaches a stable value after approximately $300 \mathrm{~m}$. It can be seen that COF characteristic is the smoothest for 10 and $12 \mathrm{~N}$ at $30 \mathrm{~mm} / \mathrm{s}$. However, at low speed, the friction coefficient characteristic shows the greatest instabilities.
The lowest COF (0.074) occurs for $10 \mathrm{~N} 30 \mathrm{~mm} / \mathrm{s}$ and the highest (0.149) occurs in all others cases.

The load-speed sensitivity of COF and friction stability are considered in order to compare the performance materials under investigation as seen in Fig. 6. The salient observations are:

- COF versus sliding distance curves show similar characteristic for all the tests carried out, a transient period followed by a single steady-state regime (Fig. 6a-d);

- COF of the studied materials is in the range of 0.04-0.18. There is less variation of $\mathbf{C O F}$ for the materials with $\mathrm{SiO}_{2}$ nanoparticles compared with materials without. SAE 49P leads to higher COF than $\mathrm{S}_{1-4}$. Furthermore, the materials with $\mathrm{SiO}_{2}$ nanoparticles have the lowest value;

- with the increased load at lowest speed (15 mm/s) (Fig. 6c), the COF of $\mathrm{S}_{1}, \mathrm{~S}_{2}$ and SAE 49P increases. It also exhibits the highest COF as compared to $S_{3}$ and $S_{4}$;

- with the increased load at highest speed $(30 \mathrm{~mm} / \mathrm{s})$, the COF of SAE 49P, $S_{3}$ and $S_{4}$ increases (Fig. 6d). Nevertheless, COF of $S_{1}$ and $S_{2}$ reaches a steady value.

In general, COF of $S_{3}$ and $S_{4}$ is smaller for the materials nanoparticles addition, than all other materials for most conditions. In our study, experimental proofs have established that: friction coefficient of all studied specimens versus sliding distance is generally lower than those of conventional material (SAE49P) [22-24].

However, for all experiments, COF shows similar characteristic for an initial transient period followed by a steady state regime. Initially, there is a run metal to metal contact that takes place due to an inadequate and unstable oil film between mating surfaces, resulting in high friction coefficients. However, as the sliding distance increases, the stable oil film forms and its thickness increases giving rise to less metal-to-metal contact. When the thickness of the oil film becomes sufficient to separate the mating surfaces substantially, the friction coefficient reaches almost constant level. The average values of the friction coefficients for all the studied specimens range from 0.04 to 0.1 . It can be concluded that 

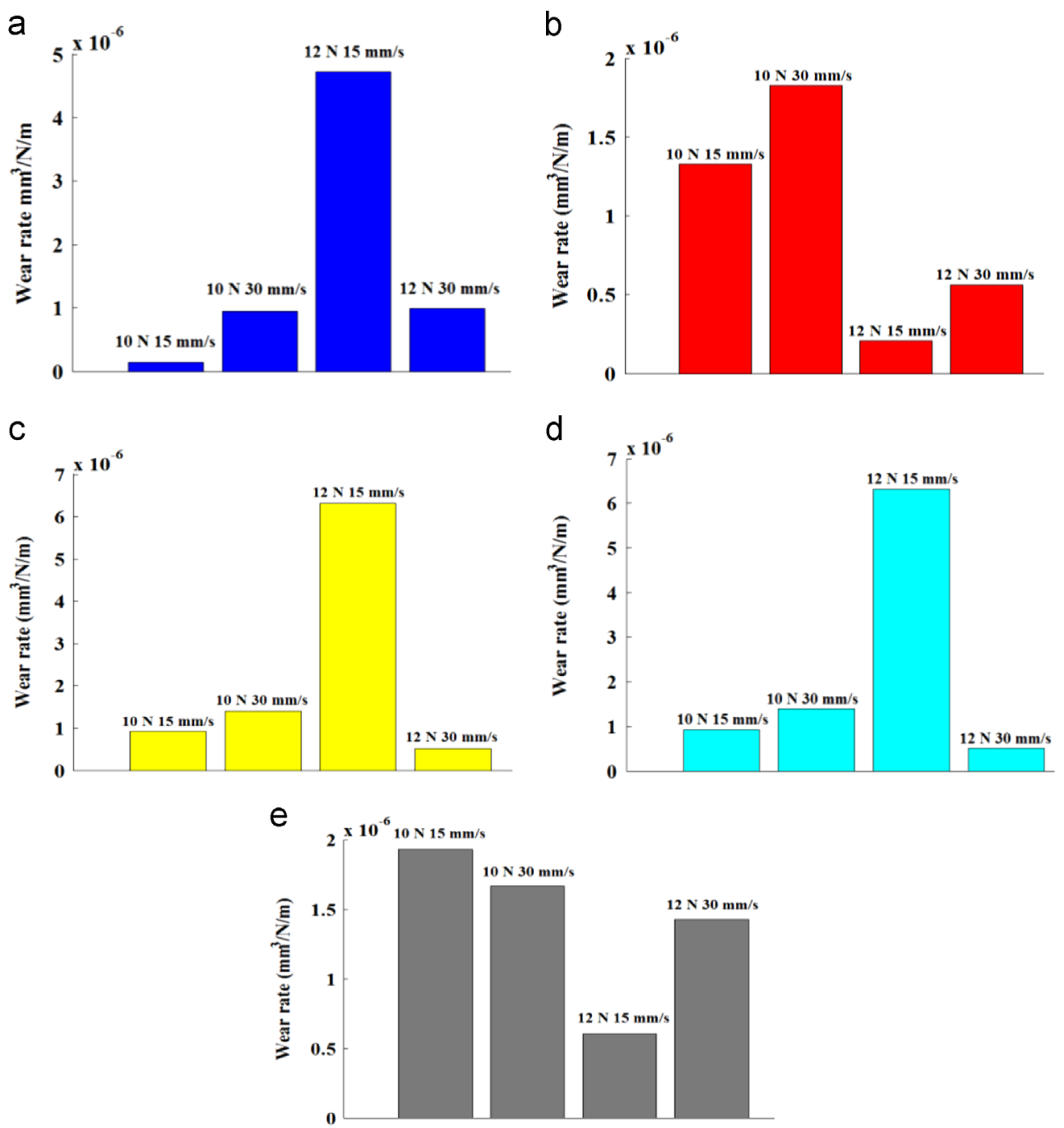

Fig. 7. Variation of wear rate of materials: (a) $S 1$, (b) $S_{2}$, (c) $S_{3}$, (d) $S_{4}$, (e) SAE 49P.

the friction coefficient of the specimens with $\mathrm{SiO}_{2}$ nanoparticles is lower than that one of the specimens without nanoparticles [2831]. The addition of nanoparticles is better suited to create a positive synergetic effect in terms of tribological performance. In the composite, the reinforcement particles support the load to reduce the touch area between the ball and the studied specimen's surface and to decrease the friction coefficient. It can also prevent the scratch and cut from the surface.

\subsection{Wear results}

Alternating the sliding speed and the applied loads reveals different wear regimes for the copper modified materials. Fig. 7a depicts the variation of $S_{1}$ wear rate.

As it can be seen from this figure, an increase of sliding speed at the applied load of $10 \mathrm{~N}$ results in an increase of the wear rate. However, at applied load of $12 \mathrm{~N}$, the wear rate decreases as the sliding speed increases. Similar behaviour is exhibited by $S_{3}$ and $S_{4}$ (Fig. 7c-d). It is also observed that $S_{2}$ exhibits the lowest wear rate with an increase in load for the same speeds.

In addition, an increase of sliding speed results in a relative increase of the wear rate of $S_{2}$ for the same applied load (Fig. 7b). When the sliding speed increases for the normal load of $10 \mathrm{~N}$, a similar trend in the wear rate for all the materials is noticed, except for the conventional material, which shows the lowest wear rate with the increase of the sliding speed (Fig. 7e). The wear rate for $S_{1} S_{3}$ and $S_{4}$ at the applied normal load of $12 \mathrm{~N}$ decreases significantly with the increase of the sliding speed (Fig. 7a, c and d). At the same load, an increase in the sliding speed results in a relative decrease of the wear rate of $\mathrm{S}_{2}$ and SAE 49P (Fig.7b and e).

Considering the wear rate of the conventional bearing, the rate of the alloy (SAE 49P) is high compared with the other alloys for the same applied conditions. The wear rate of all the materials is plotted as a function of the applied normal load and the sliding speed as shown in Fig. 8. At the initial stages (low load $10 \mathrm{~N}$ and low speed $15 \mathrm{~mm} / \mathrm{s}$ ), the highest wear rate occurs in SAE 49P whereas the lowest value occurs in $S_{3}$ (Fig. 8a). With an increase sliding speed at the same applied load, the highest wear rate occurs in $S_{2}$ and the lowest in $S_{3}$ (Fig. 8 b). However, with the increase load (12 N) at the sliding speed of $15 \mathrm{~mm} / \mathrm{s}$, the highest wear rate occurs in $\mathrm{S}_{4}$ and the lowest in $\mathrm{S}_{2}$ (Fig. 8c). At the same load $(12 \mathrm{~N})$ and an increase in the sliding speed $(30 \mathrm{~mm} / \mathrm{s})$, the highest wear rate occurs in conventional material (SAE 49P) while the lowest wear rate in $S_{4}$ (Fig. 8d).

\subsection{Worn surfaces characterization}

To further understand the wear mechanism, the surface of the counterpart steel rings, which has rubbed against the studied specimens, is also analysed by SEM (Figs. 9-13). Fig. 9a and b shows a surface morphology of $S_{1}$ at the applied load of $10 \mathrm{~N}$ the sliding speeds of $15 \mathrm{~mm} / \mathrm{s}$ and $30 \mathrm{~mm} / \mathrm{s}$ respectively. It can be 

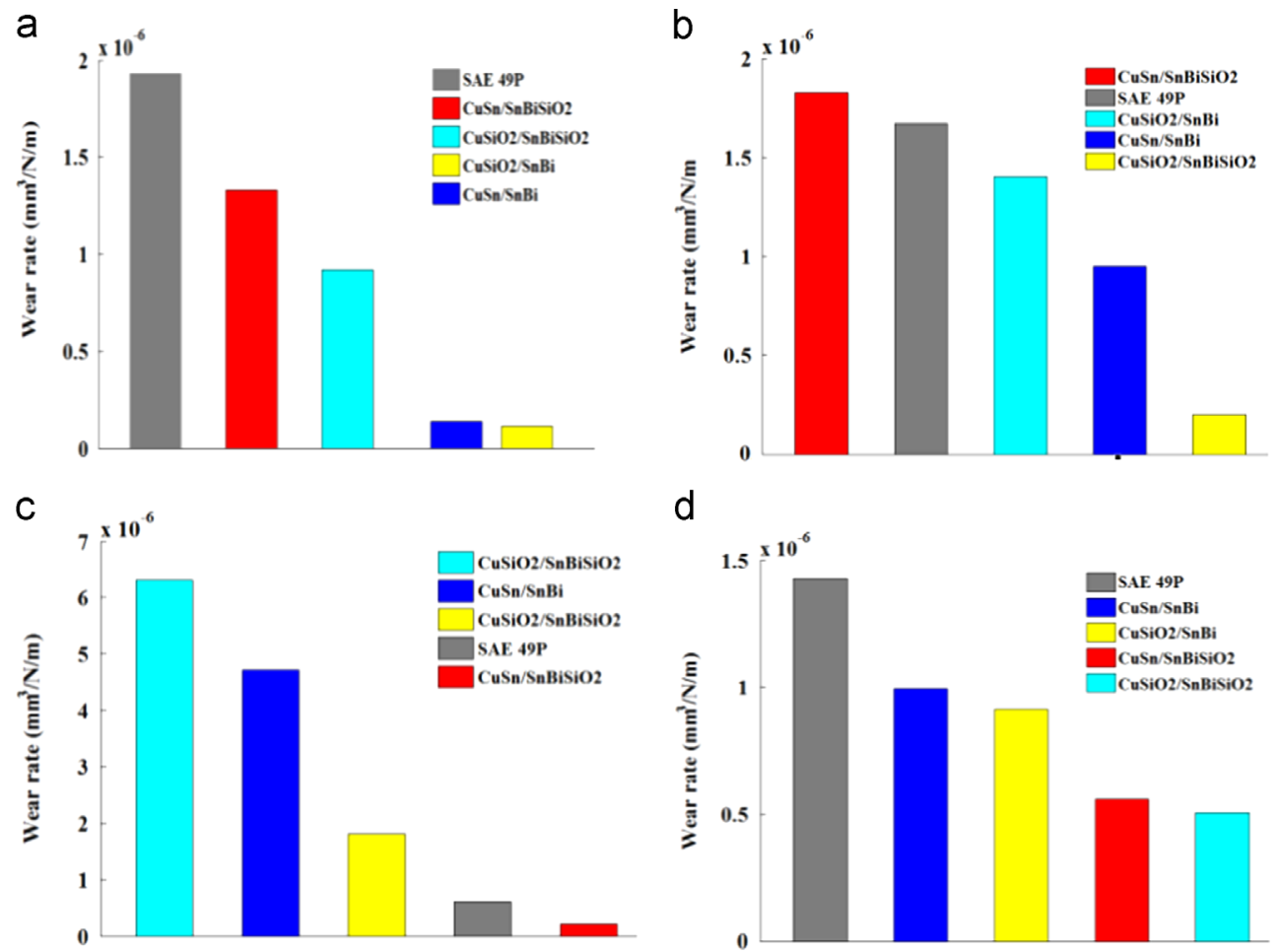

Fig. 8. Evolution of wear rate of all materials at: (a) $10 \mathrm{~N} 15 \mathrm{~mm} / \mathrm{s}$, (b) $10 \mathrm{~N} 30 \mathrm{~mm} / \mathrm{s}$, (c) $12 \mathrm{~N} 15 \mathrm{~mm} / \mathrm{s}$, (d) $12 \mathrm{~N} 30 \mathrm{~mm} / \mathrm{s}$.
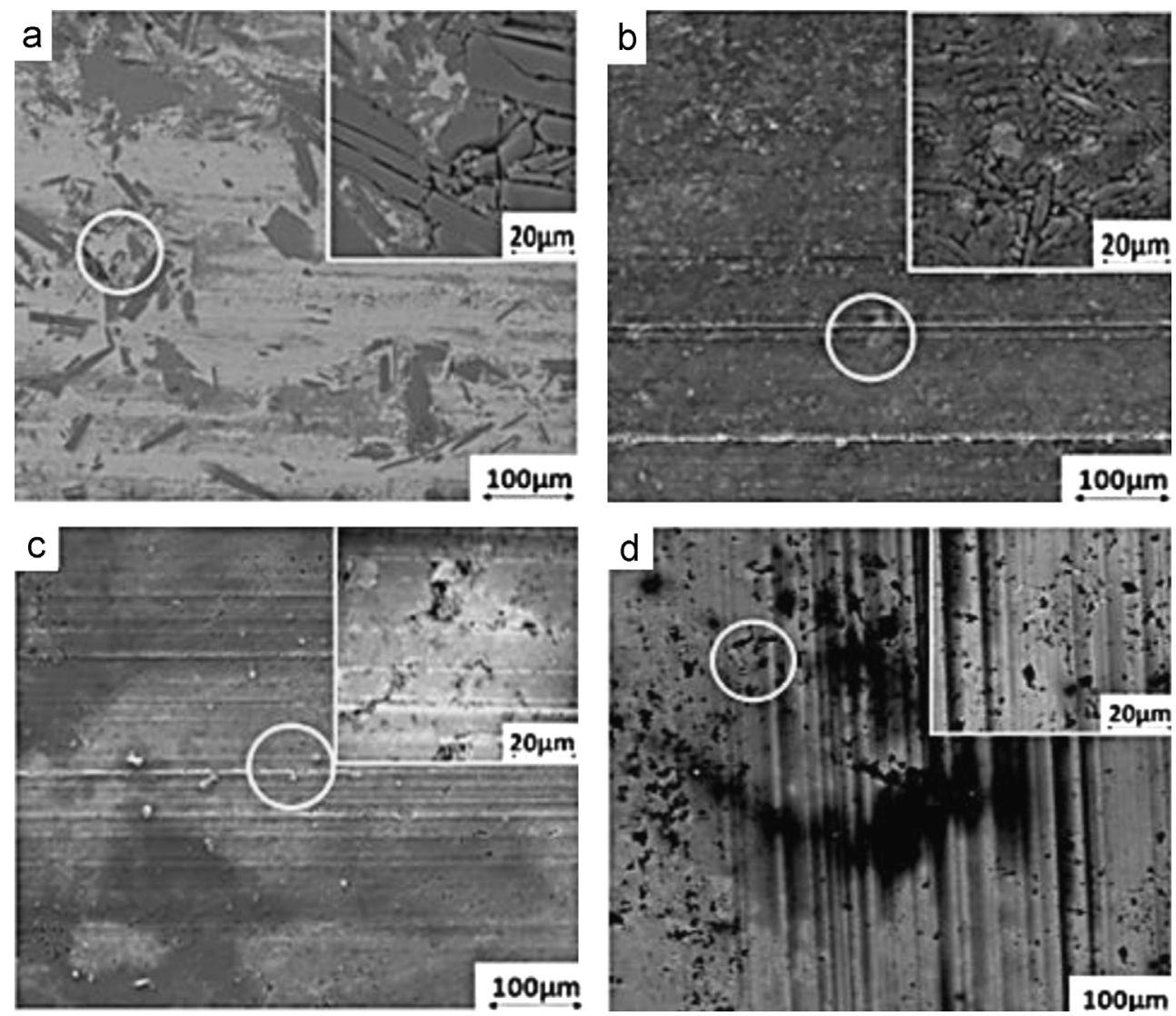

Fig. 9. SEM micrographs of worn surface of $S_{1}$ at: (a) $10 \mathrm{~N} 15 \mathrm{~mm} / \mathrm{s}$, (b) $10 \mathrm{~N} 30 \mathrm{~mm} / \mathrm{s}$, (c) at $12 \mathrm{~N} 15 \mathrm{~mm} / \mathrm{s}$, (d) $12 \mathrm{~N} 30 \mathrm{~mm} / \mathrm{s}$.

noticed that there are large areas of plastic deformation implying the occurrence of a dominant adhesive wear mechanism [28]. The low wear rates and smooth worn surfaces are mainly due to the combination of self-lubrication function of $\mathrm{Bi}$ particles in the friction process and porosity. It can be seen that the porous surface enables it to absorb more lubricant. As a result, the absorbed lubricant reduces the direct contact of the sliding couple; hence, the wear rate is reduced. With the increase of the applied load, the 

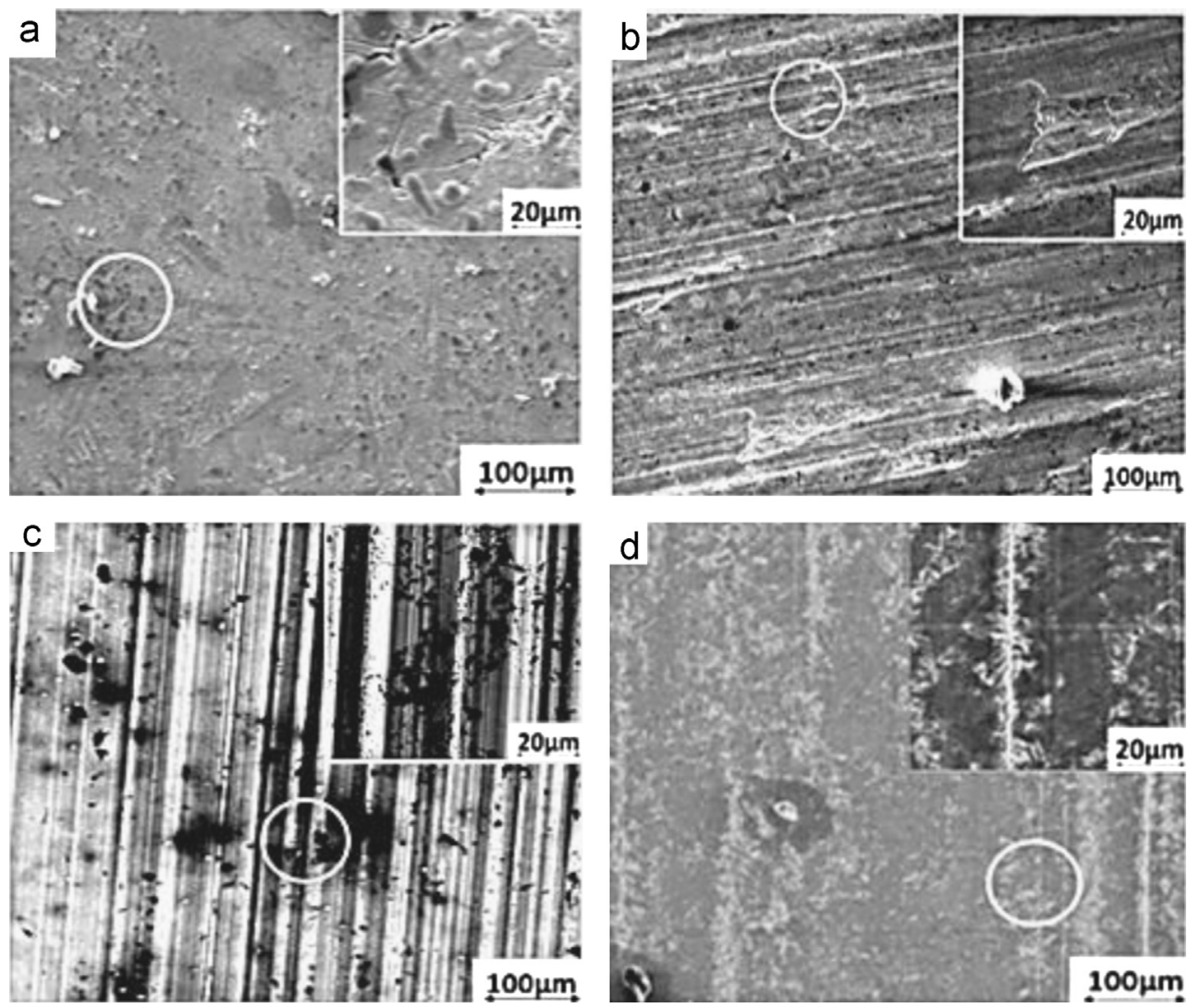

Fig. 10. SEM micrographs of worn surface of $\mathrm{S}_{2}$ at: (a) $10 \mathrm{~N} 15 \mathrm{~mm} / \mathrm{s}$, (b) $10 \mathrm{~N} 30 \mathrm{~mm} / \mathrm{s}$, (c) $12 \mathrm{~N} 15 \mathrm{~mm} / \mathrm{s}$, (d) $12 \mathrm{~N} 30 \mathrm{~mm} / \mathrm{s}$.
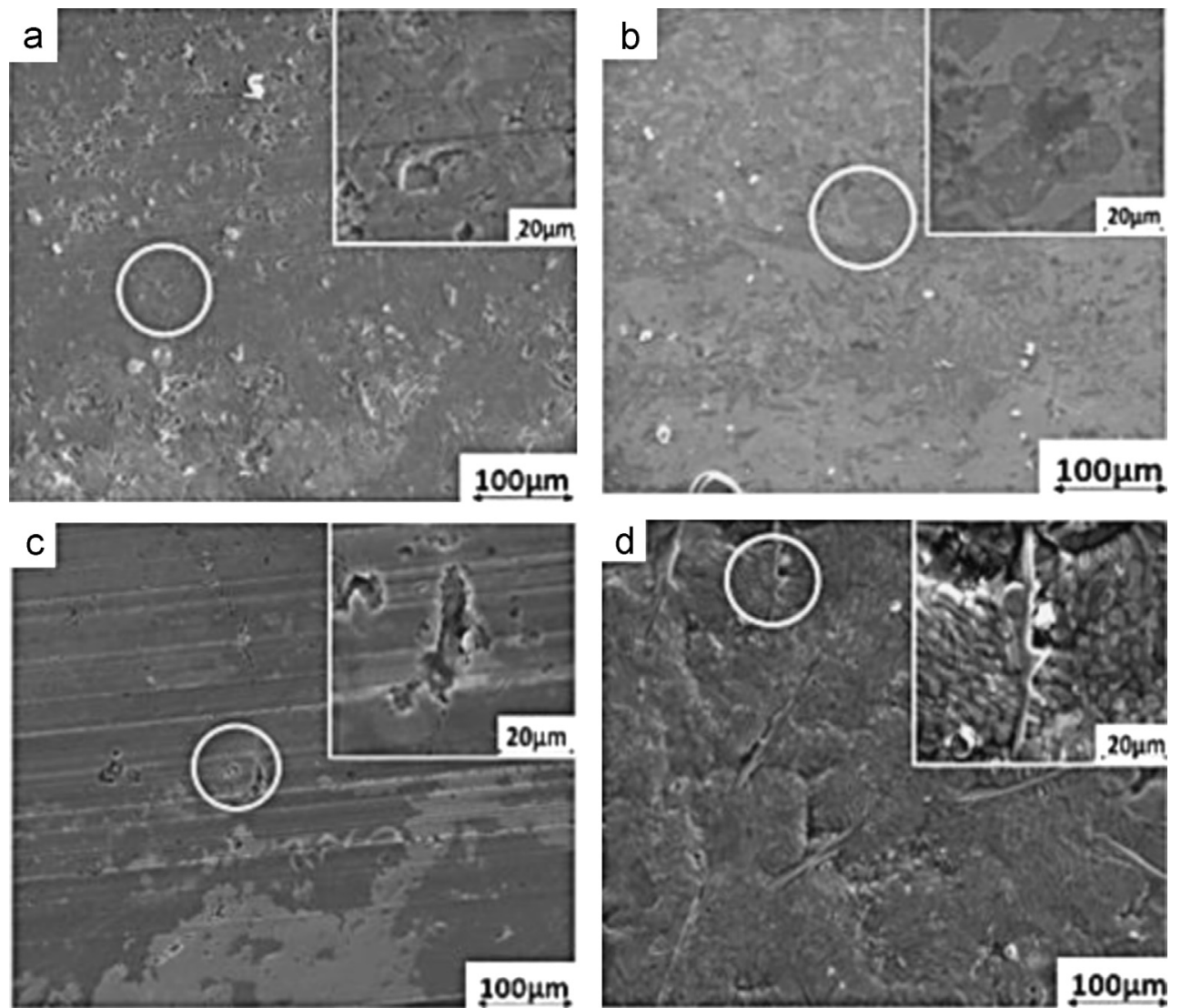

Fig. 11. SEM micrographs of worn surface of $\mathrm{S}_{3}$ at: (a) $10 \mathrm{~N} 15 \mathrm{~mm} / \mathrm{s}$, (b) $10 \mathrm{~N} 30 \mathrm{~mm} / \mathrm{s}$, (c) $12 \mathrm{~N} 15 \mathrm{~mm} / \mathrm{s}$, (d) $12 \mathrm{~N} 30 \mathrm{~mm} / \mathrm{s}$. 

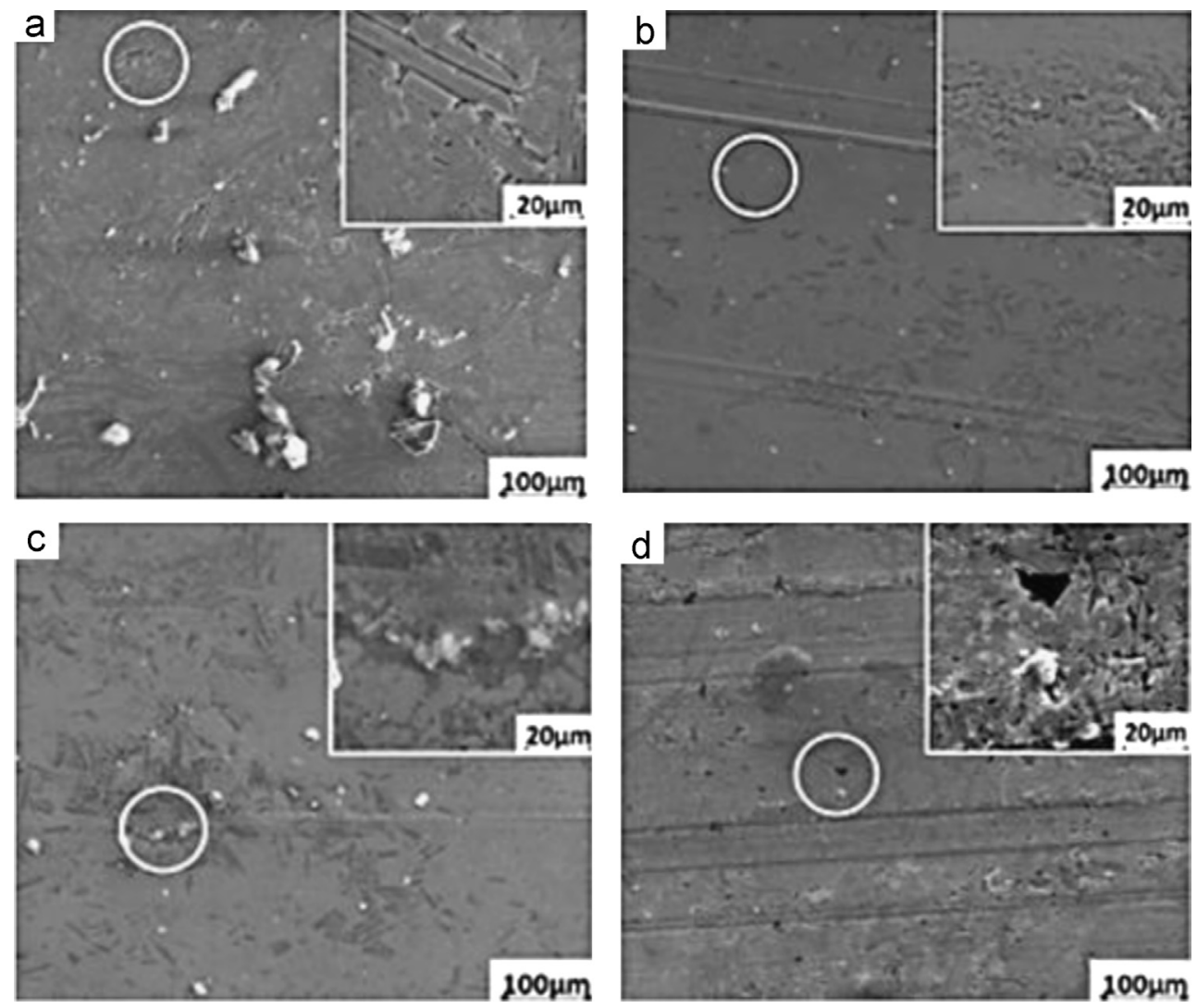

Fig. 12. SEM micrographs of worn surface of $\mathrm{S}_{4}$ at: (a) $10 \mathrm{~N} 15 \mathrm{~mm} / \mathrm{s}$, (b) $10 \mathrm{~N} 30 \mathrm{~mm} / \mathrm{s}$, (c) $12 \mathrm{~N} 15 \mathrm{~mm} / \mathrm{s}$, (d) $12 \mathrm{~N} 30 \mathrm{~mm} / \mathrm{s}$.
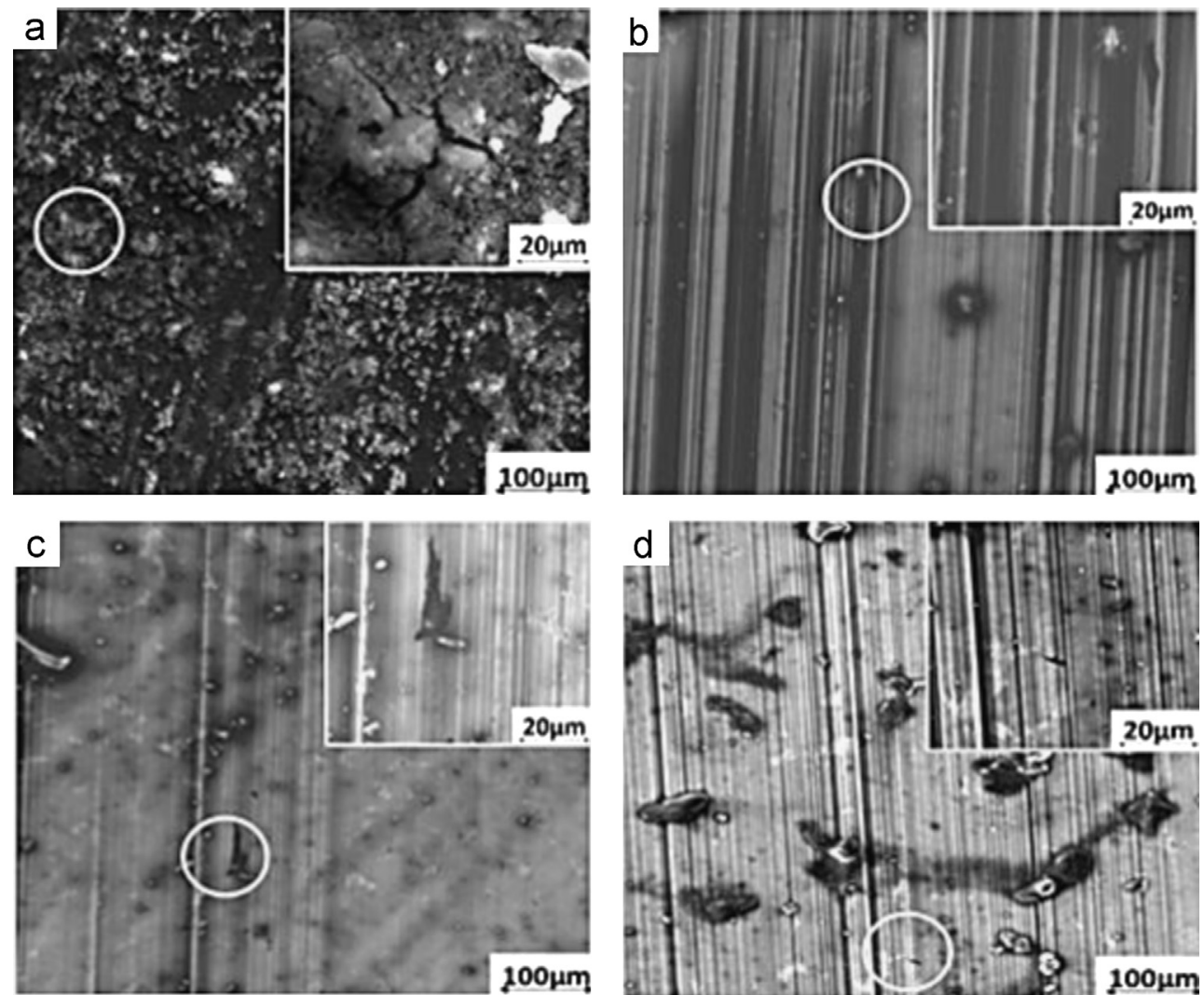

Fig. 13. SEM micrographs of worn surface of SAE 49P at: (a) $10 \mathrm{~N} 15 \mathrm{~mm} / \mathrm{s}$, (b) $10 \mathrm{~N} 30 \mathrm{~mm} / \mathrm{s}$, (c) t $12 \mathrm{~N} 15 \mathrm{~mm} / \mathrm{s}$, (d) $10 \mathrm{~N} 15 \mathrm{~mm} / \mathrm{s}$. 
a

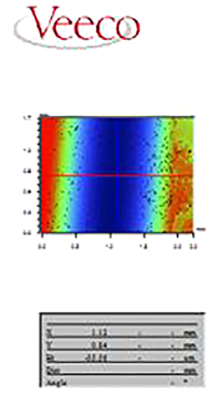

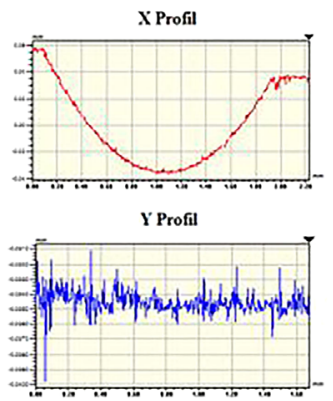

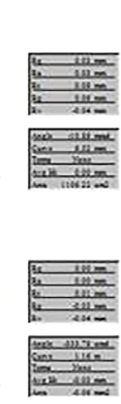

b

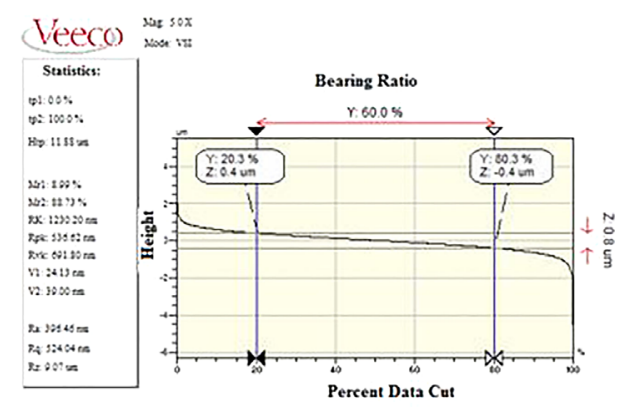

Fig. 14. surface's profil obteined by interferrometre profiler Wyko NT9300: (a) Profil 2D, (b) Abbot curve.

Table 2

Statical data roughness and bearing ratio for surface of specimen's before wear test.

\begin{tabular}{lclcl}
\hline Materials & \multicolumn{2}{c}{ Surface roughness parameters } & \multicolumn{2}{c}{ Bearing ratio parameters } \\
\hline & $R_{\mathrm{z}}(\mu \mathrm{m})$ & $R_{\mathrm{t}}(\mu \mathrm{m})$ & $\operatorname{Mr} 1(\%)$ & $\mathrm{Mr}(\%)$ \\
$\mathrm{S}_{1}$ & 9.07 & 2.16 & 8.99 & 86.17 \\
$\mathrm{~S}_{2}$ & 9.55 & 2.21 & 10.86 & 86.52 \\
$\mathrm{~S}_{3}$ & 11.95 & 2.45 & 9.91 & 86.44 \\
$\mathrm{~S}_{4}$ & 9.85 & 2.8 & 10.25 & 86.78 \\
$\mathrm{SAE} 49 \mathrm{P}$ & 20.4 & 9.73 & 10.02 & 94.69 \\
\hline
\end{tabular}

large plastic deformation appears in the contact surfaces. The two surfaces are prone to stick to each other due to the heat friction that is induced by rubbing, thus leading to a higher friction. Since $S_{1}$ material is softer than the ball, the former is plastically deformed more easily. The significant cracking action of the weak regions indicates the effect of the plastic deformation during the abrasion wear, as they appear parallel to the sliding motion (Fig. 9c).

The smearing and scratches along the sliding direction depict the worn surface in Fig. 9d. The back transfer of the contact surface from the ball to the sample surface produces the smearing while the ploughing action of the hard particles and the wear particles formed during sliding produce the scratched area [37].

The examination of the worn surface of $S_{2}$ at $10 \mathrm{~N}$ and sliding speeds (15 and $30 \mathrm{~mm} / \mathrm{s}$ ) presents a significant adhesion (Fig. 10ab). At the same time, the debris look like chips and a linear relief appears with sharp edged asperities and scoring. In these cases, the wear pattern is typical for the running process accompanied by intensive wear. Fig. 10c and d presents the worn surfaces of $\mathrm{S}_{2}$ at $12 \mathrm{~N}$ showing that the abrasive wear is dominant. It can be seen from these figures that the continuous wide grooves and the considerable extent of microcuttings are deep on the worn surfaces. Fines debris particles also appear to stick to the surface (Fig. 10c) and can be attributed to the pull-out of the hard particles of $\mathrm{SiO}_{2}$. These particles penetrate the surfaces and displace the elongated chips of the materials. However, the fine particles of $\mathrm{SiO}_{2}$ can improve the wear resistance by hindering the deformation of the material during the sliding process [30,31].

The adhesion with the shearing and the crater of the fragile plates in the worn surface of $S_{3}$ are observed for $10 \mathrm{~N} 15 \mathrm{~mm} / \mathrm{s}$ (Fig. 11a). The smooth and the compact worn surfaces in Fig. 11b indicate that the wear mechanism is mainly dominated by adhesion. Fig. 11c shows the worn surface of $S_{3}$ at $12 \mathrm{~N} 15 \mathrm{~mm} / \mathrm{s}$, which is deformed plastically, and also illustrates the presence of few grooves with some large flaking pits. Clearly, the worn surface of $\mathrm{S}_{3}$ at the lowest normal load becomes more compact. The compact films can effectively decrease the direct contacting area between the $\mathrm{Cu}$-based composites and the counter-surface; therefore, improving the wear resistance of the Cu-based composites. Fig. 11d shows that the worn surface at the higher condition is relatively rough and exhibits plastic deformation.

Fig. 12 shows the SEM micrographs of the worn surface of $\mathrm{S}_{4}$ where the plough and the plastic deformation are the dominant effect. It is noted that the worn surface is completely smooth and flat and it contains wear tracks in the direction of the sliding. Some abrasive particles generated from loose debris can be seen in Fig. 12a. It appears that the shearing and deformation of the fragile asperities are due to the repeated mechanical loading at the lowest conditions. The peeling off and the breakage are the dominant wear modes, implying that a major share of the normal load was supported by the materials. The micro-abrasion phenomena with scars and layers are observed in the worn surface of $S_{4}$ at $10 \mathrm{~N}$ $30 \mathrm{~mm} / \mathrm{s}$ (Fig. 12b). From Fig. 12c, the worn surface of $S_{4}$ appears smooth and exhibits rather irregular and shallow sliding marks with more fine debris particles also appearing to be stuck to the surface. The worn surface is relatively rough, and exhibits rather irregular and deep sliding marks with cracked edges. In addition, some dimples and large pits can be seen on the surface of the tracks caused by the cutting action of the abrasive particles generated from loose debris (Fig. 12d).

Fig. 13 shows the presence of multiple parallel scratches or deep grooves of the track in the worn surfaces of the conventional material (SAE 49P) under the different test conditions. The features observed on the wear surfaces of the samples at the higher conditions are identical to those at the lower conditions. The abrasion on the worn surface of conventional material appears to be dominant practically under all testing conditions.

Fig. 13a illustrates that compacted asperities and large grains partially remain and connect together the studied specimen's surface network formation body, which ensure a good bonding between the coating and the substrate rough surface with deep microcracks. A severe abrasion damage is observed on the wear surfaces (Fig. 13b) whose severity decreases as the test's speed increases. Fig. 13c shows some detachment of debris and Fig. 13d indicates the presence of microcracks and debris adhesion to the wear surface.

It is well known that the wear process generally experiences three stages: surface interaction, surface damage and wearing pullout. The wear types mainly include abrasion, oxidation, delamination, adhesion, and thermal softening and melting [3840]. Indeed, Bowden and Tabor [9] proposed that the two main contributing factors to friction generated during sliding wear could be described by (i) adhesion of flat regions of the sliding surfaces and (ii) abrasion by wear particles and hard asperities. Other researchers [37] argued that a third term should be introduced, namely the deformation of the surface asperities. Actually, abrasion can be regarded as a kind of plastic deformation. At this point, the dominant wear mechanism is the adhesive wear accompanied by a mild abrasive wear. Adhesive wear occurs at the 

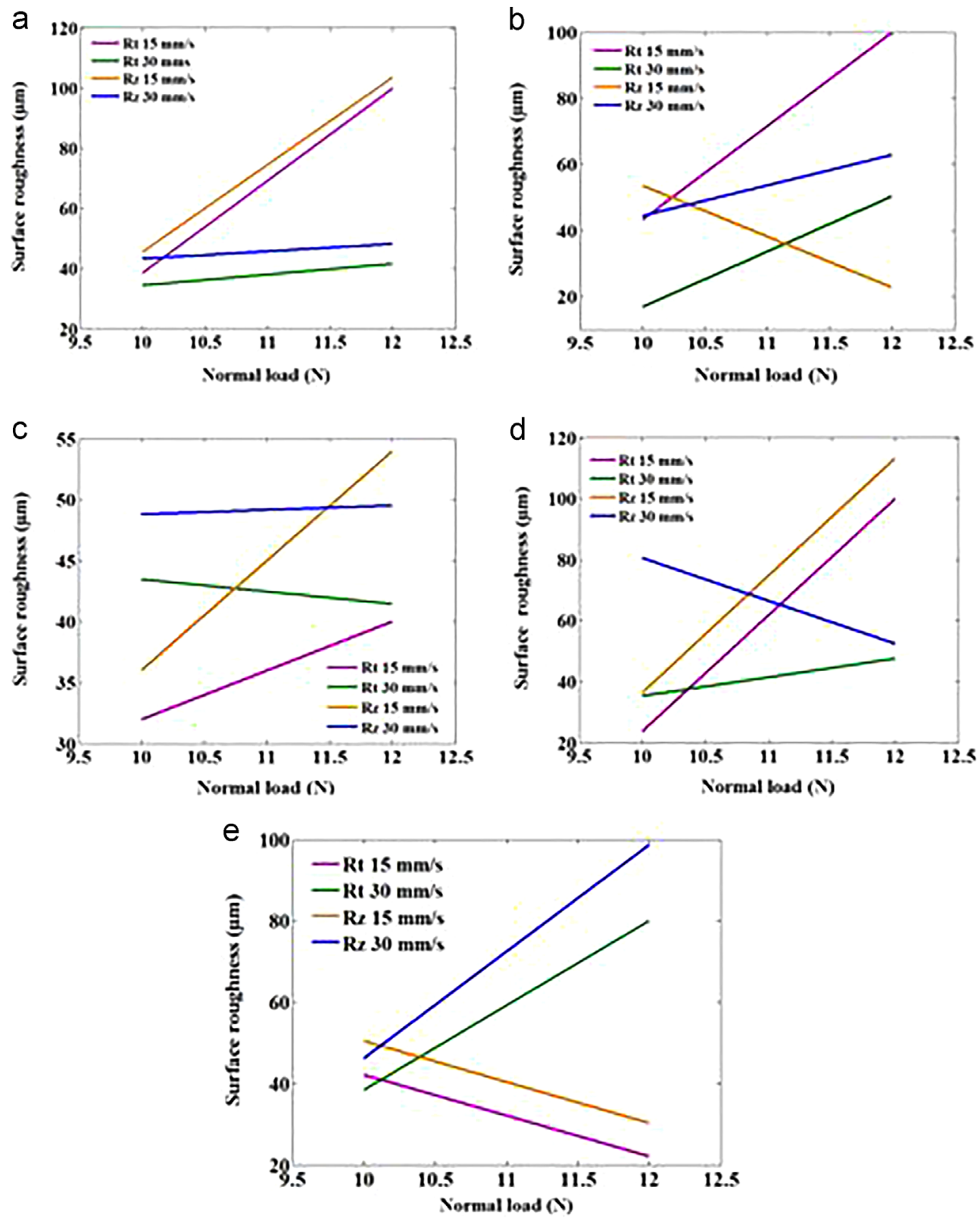

Fig. 15. Evolution of $R_{\mathrm{t}}$ and $R_{\mathrm{z}}$ versus applied load: (a) $\mathrm{S}_{1}$, (b) $\mathrm{S}_{2}$, (c) $\mathrm{S}_{3}$, (d) $\mathrm{S}_{4}$, (e) SAE 49P.

asperity contacts at the interface and these contacts are sheared by sliding. This process may result in a detachment of fragments from one surface and an attachment to the other surface [28-31].

Note that no clear correlation is found between friction and wear. Indeed samples $\mathrm{S}_{4}$ (Figs. $6 \mathrm{c}$ and $8 \mathrm{c}$ ) exhibit the lowest friction but the highest wear. The current results suggest that friction occurs essentially from the subsurface deformation that does not necessarily lead to the wear debris and (wear) detachment. Furthermore, the debris detached from the deformed materials can remain trapped within the surface contact and smear on the contact surface.

\subsection{Influence of rugosity}

The surfaces of the different materials under investigation have been analysed for surface quality before and after the tests of friction-wear using the profiler Wyko NT9300's graphical tools (Fig. 14) [41]. Effective surface profile evaluations have been carried out with the help of the recognised statistical descriptors of height where $R_{\mathrm{z}}$ is the average maximum height from individual peak to valley, and $R_{\mathrm{t}}$ is the maximum distance between the highest peak and the lowest valley [42-43]. The Abbot curve or bearing ratio is defined as the ratio of the length of the surface at a specified depth of the profile to the overall length. This evaluation is based on the bearing ratio curves. Mr1 and Mr2, that are the upper and lower volume of fluid retention, determine the extent of surface's profile. The basic statistics of the surface roughness $\left(R_{\mathrm{z}}\right.$ and $\left.R_{\mathrm{t}}\right)$ and bearing ratio of the surfaces $\left(\mathrm{Mr}_{1}\right.$ and $\left.\mathrm{Mr}_{2}\right)$ of $\mathrm{S}_{1}, \mathrm{~S}_{2}, \mathrm{~S}_{3}$, $\mathrm{S}_{4}$ and SAE 49P before the wear test are shown in Table 2. The properties of the solid surfaces are crucial to the surface interaction because they affect the real area of contact, friction, wear, and lubrication. On the other hand, an isolated analysis of the roughness can lead to a false characterization of the tribological phenomena. $R_{\mathrm{t}}$, maximum peak to valley, is very sensitive to small variation in the profile and gives information on the length characteristics.

Fig. 15a-e shows the variation of $R_{\mathrm{t}}$ and $R_{\mathrm{z}}$ of $\mathrm{S}_{1}, \mathrm{~S}_{2}, \mathrm{~S}_{3}, \mathrm{~S}_{4}$ and SAE 49P respectively. One can conclude that at the lower sliding 

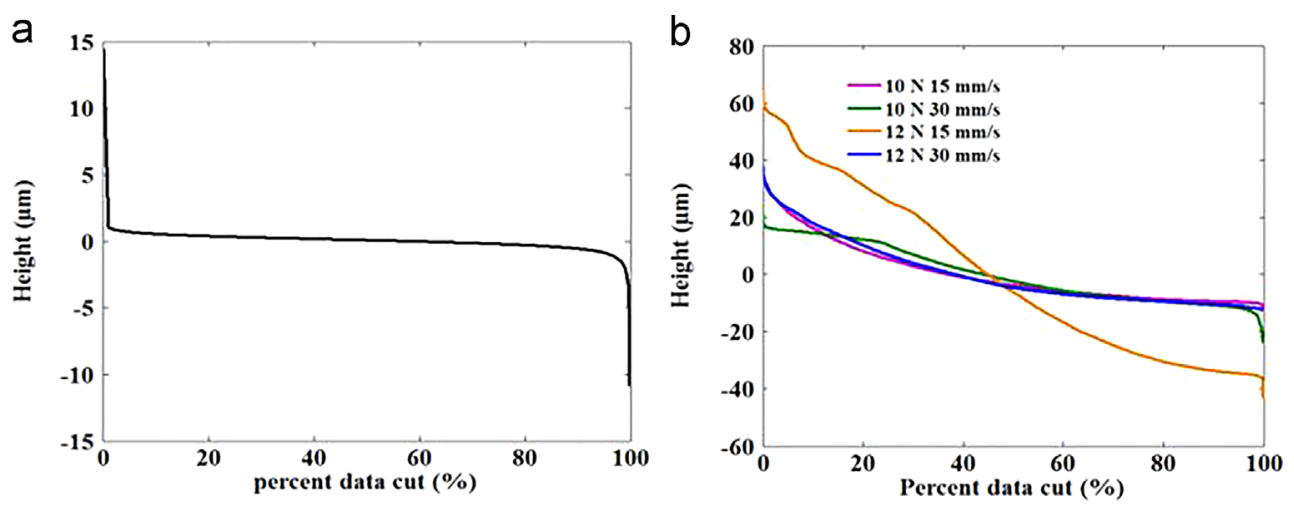

Fig. 16. Evolution of Abbot curves of $S_{1}$ : (a) before sliding tests, (b) after sliding under different applied conditions tests.
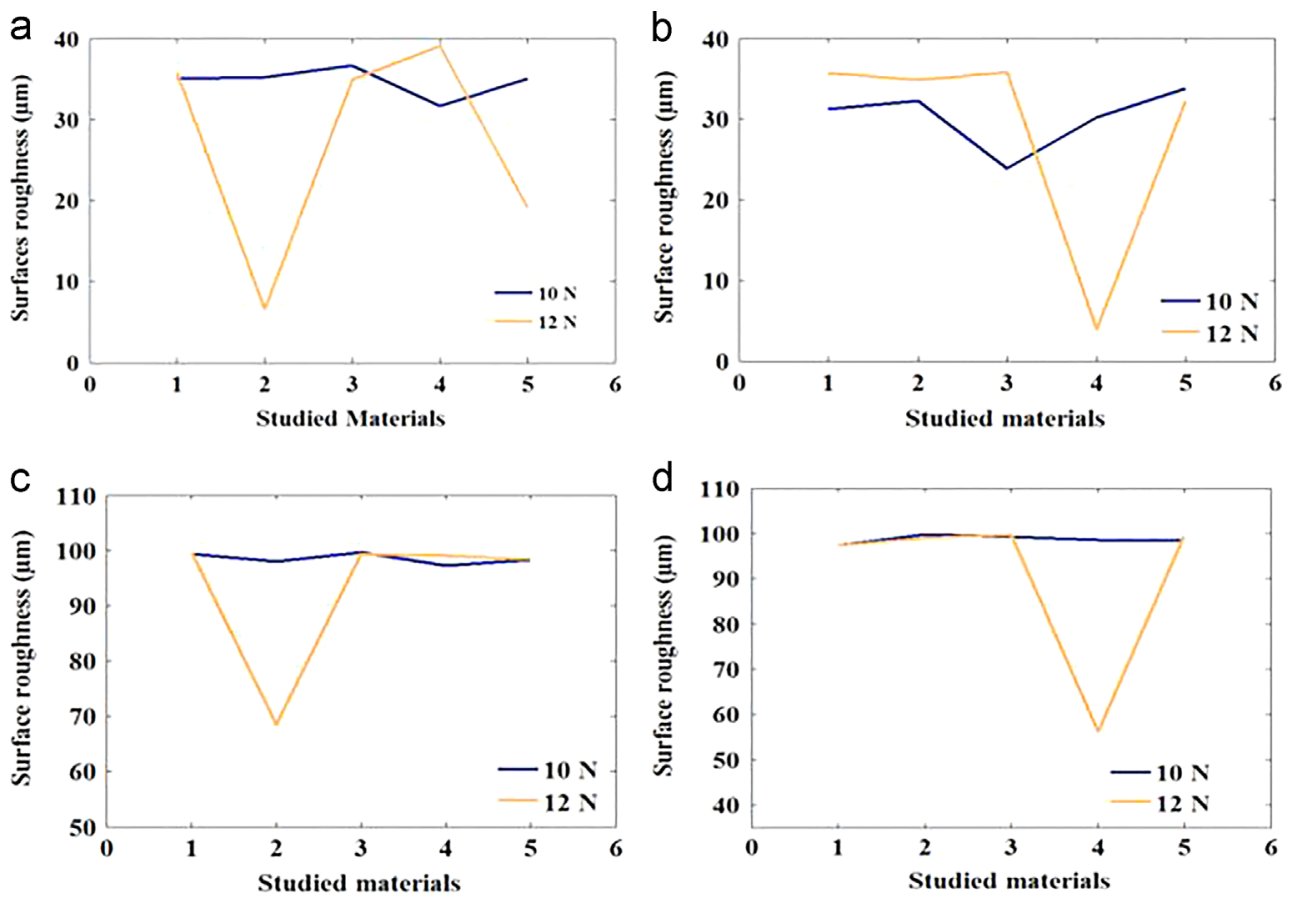

Fig. 17. Evolution of all materials: (a) Mr1 at $15 \mathrm{~mm} / \mathrm{s}$, (b) Mr1 at $30 \mathrm{~mm} / \mathrm{s}$, (c) Mr2 at15 mm/s, (d) Mr2 at $30 \mathrm{~mm} / \mathrm{s}$.

speed, $R_{\mathrm{t}}$ and $R_{\mathrm{z}}$ of $\mathrm{S}_{1}$ (Fig. 15a) increase with an increase in the applied load. At the highest sliding speed, $R_{\mathrm{t}}$ and $R_{\mathrm{z}}$ observed a light increase with an increased in the applied load. The sensitive parameters $R_{\mathrm{t}}$ of $\mathrm{S}_{2}$ (Fig. 15b) increase with an increase in the applied load but the values of $R_{\mathrm{z}}$ varies inversely with the applied load at $15 \mathrm{~mm} / \mathrm{s}$.

However, $R_{\mathrm{t}}$ and $R_{\mathrm{z}}$ increase significantly with the applied load at $30 \mathrm{~mm} / \mathrm{s}$. Fig. $15 \mathrm{c}$ depicts that $R_{\mathrm{t}}$ and $R_{\mathrm{z}}$ of $\mathrm{S}_{3}$ at $15 \mathrm{~mm} / \mathrm{s}$ increase with an increase of the load. However, at highest sliding speeds, the sensitive parameters remain practically constant. Fig. 15d shows that $R_{\mathrm{t}}$ and $R_{\mathrm{z}}$ of $\mathrm{S}_{4}$ reach their maximum value at the applied load of $12 \mathrm{~N}$ and the lowest sliding speed. However, at $30 \mathrm{~mm} / \mathrm{s}, R_{\mathrm{t}}$ increases proportionally with the applied load and $R_{\mathrm{z}}$ changes inversely with the increase of the applied load. The sensitive parameters $R_{\mathrm{t}}$ and $R_{\mathrm{z}}$ of SAE 49P (Fig. 15e) reach their minimum values at the load of $12 \mathrm{~N}$ and speed $15 \mathrm{~mm} / \mathrm{s}$ and the maximum value at the same load and speed $30 \mathrm{~mm} / \mathrm{s}$.

Fig. 16a shows the Abbot curves of $S_{1}$, before the wear tests. It can be noted that the surfaces of all materials have smooth distribution of the bearing surface with a single slope in the middle, which is a feature of the polished surfaces. Nonetheless, the sliding wear alters the surface's distribution significantly by producing an initial peak and introducing several slopes in the middle of the curve as observed in Fig. 16b. It is not clear whether these irregularities have significantly contributed to the worn surface [44]. However, they increase the number of peaks and the magnitude of the local peaks whose distribution is nonuniform. The similar phenomena occurs for all the other materials $\left(\mathrm{S}_{2}, \mathrm{~S}_{3}, \mathrm{~S}_{4}\right.$, and SAE49P respectively) after the wear tests are observed. The formation of peaks implies an increase in the number of slopes.

Mr1 and its variation with normal load during sliding in different materials investigated under sliding speed of $15 \mathrm{~mm} / \mathrm{s}$ and $30 \mathrm{~mm} / \mathrm{s}$ are shown in Fig. 17a and b respectively. Mr1 characterizes the fraction of the surface, which consists of small peaks above the main plateau. It is observed that for $S_{3}, \operatorname{Mr} 1$ is higher compared to all other materials and it has the lowest value for $\mathrm{S}_{4}$, except for the load of $12 \mathrm{~N}$ at the sliding speed of $15 \mathrm{~mm} / \mathrm{s}$ where surprisingly $S_{2}$ has the lowest value of Mr1 and $S_{4}$ keeps the highest Mr1 (Fig. 17a).

The evolution of the fraction of the surface, which will carry the load during the practical lifetime of $\mathrm{Mr} 2$, is seen in Fig. 17c and d. It is perceived, that the area, available in the inner recess for lubrication purposes in all materials, remains fairly negligible, 
almost null with increasing load, at around (100-Mr2)\%, 0\%. With exception of $S_{2}$, this area increases significantly with increasing load at $15 \mathrm{~mm} / \mathrm{s}$ as Fig. 17c. The same phenomenon is observed for $\mathrm{S}_{4}$ at sliding speed of $30 \mathrm{~mm} / \mathrm{s}$ in Fig. $17 \mathrm{~d}$.

\section{Conclusion}

Four configurations of mild steel/CuSn/SnBi multimaterials system were fabricated by powder metallurgy process with addition 1 wt\% of $\mathrm{SiO}_{2}$ nanoparticle. The tribological properties of these four studied specimens were improved in comparison with conventional material for journal bearing, which were investigated by lubricated sliding test against $100 \mathrm{C} 6$ ball at ambient atmosphere. Based on the results obtained in this work, the following conclusions can be drawn:

- Under the same test conditions, the friction coefficients of the materials under investigation have similar variation trend.

- The friction coefficient of the four specimens is in the range 0.04-0.1, which is much lower than that of reference SAE 49P (in the range 0.12-0.16); The lowest friction coefficient occurs in most conditions of $\mathrm{S}_{3}$ and/or $\mathrm{S}_{4}$.

- The Highest wear rate and friction coefficient in most applied conditions occurs in the reference material.

- The lowest friction coefficient and wear rate occurs in most condition of the studied specimens with $\mathrm{SiO}_{2}$ nanoparticles $\left(\mathrm{S}_{2}\right.$, $\mathrm{S}_{3}$ and $\mathrm{S}_{4}$ ).

- The wear rate increases with an increase in sliding speed and decreases with an increase in applied load; the wear rate of the reference material decreases with an increase in applied load. However, at the lowest applied load, the wear rate decreases with an increase in sliding speed, and at the highest applied load, the wear rate increases with an increase in sliding speed.

- The dominant wear mechanism is the adhesive wear, accompanied by a mild abrasive wear.

- The sensitive parameters of surface profile like $R_{\mathrm{t}}$ and $R_{\mathrm{z}}$ of $\mathrm{S}_{1}$ increase with an increase in applied load at the lowest sliding speed and barely change at the highest sliding speed. One can observe an inverse behaviour in the parameter of the reference material SAE 49P under the same conditions. However, these parameters of $S_{2}, S_{3}$, and $S_{4}$ with nanoparticles addition depict abstruse variations in the same conditions. This could be due to the hard nanoparticles.

- The sliding wear alters the distribution of the surface significantly by producing an initial peak and introducing several slopes in the middle of the Abbott curve.

\section{Appendix A. Supporting information}

Supplementary data associated with this article can be found in the online version at http://dx.doi.org/10.1016/j.triboint.2015.04.034.

\section{References}

[1] Varol T, Canakci A. Effect of weight percentage and particle size of $\mathrm{B}_{4} \mathrm{C}$ reinforcement on physical and mechanical properties of powder metallurgy Al2024-B 4 C composites. Met Mater Int 2013;19:1227-34.

[2] Canakci A, Varol T. Microstructure and properties of AA7075/Al-SiC composites fabricated using powder metallurgy and hot pressing. Powder Technol 2014;268:72-9.

[3] Canakci A, Varol T, Cuvalci H, Erdemir F, Ozkaya S, Yalcın ED. Synthesis of novel CuSn10-graphite nanocomposite powders by mechanical alloying. Micro Nano Lett 2014;9:109-12.

[4] Varol T, Canakci A. Synthesis and characterization of nanocrystalline Al 2024$\mathrm{B}_{4} \mathrm{C}$ composite powders by mechanical alloying. Philos Mag Lett 2013;93:339-45
[5] Canakci A, Varol T, Nazik C. Effects of amount of methanol on characteristics of mechanically alloyed $\mathrm{Al}-\mathrm{Al}_{2} \mathrm{O}_{3}$ composite powders. Mater Technol 2012;27:320-7.

[6] Canakci A, Varol T, Ertok S. The effect of mechanical alloying on $\mathrm{Al}_{2} \mathrm{O}_{3}$ distribution and properties of $\mathrm{Al}_{2} \mathrm{O}_{3}$ particle reinforced Al-MMCs. Sci Eng Compos Mater 2012;19:227-35.

[7] Varol T, Canakci A, Ozsahin S. Modeling of the Prediction of densification behavior of powder metallurgy $\mathrm{Al}-\mathrm{Cu}-\mathrm{Mg} / \mathrm{B}_{4} \mathrm{C}$ composites using artificial neural networks. Acta Metall. Sin 2015;28:182-95.

[8] Chandrasekaran M, Singh P. Sintered iron-copper-tin-lead antifriction materials effect of temperature. Mater Sci Eng 2000;A292:26-33.

[9] Bowden FP, Tabor D. The friction and lubrication of solids. . Oxford University Press; 1964.

[10] EC. JHA A, PRASAD SV. Sintered 6061 aluminum alloy-solid lubricant particle composites: sliding wear and mechanisms of lubrication. Wear 1989;133:163-72.

[11] Kostornov AG, Fushchich OI. Effects of copper powder bearing material composition on working characteristics. Powder Metall Met Ceram 2005;44 (3-4):202-6.

[12] Canakci A, Cuvalci H, Varol T, Erdemir F, Ozkaya S, Yalcin ED. Microstructure and abrasive wear behavior of CuSn10-graphite composites produced by powder metallurgy. Powder Metall Met Ceram 2014;53:32-47.

[13] Durak E. Experimental investigation of porous bearings under different lubricant and lubricating conditions. KSME Int J 2003;17(9):1276-86.

[14] Pawlak Z, Kaldonski T, Pai R, Bayraktar E, Oloyede A. A comparative study on the tribological behaviour of hexagonal boron nitride (h-BN) as lubricating micro-particles-an additive in porous sliding bearings for a car clutch. Wear 2009;267:1198-202.

[15] Kostornov AG, Fushchich OI, Chevichelova TM. Structuration in sintering of antifriction powder materials based on iron-copper alloys. Powder Metall Met Ceram 2007;46(12):589-94.

[16] Prasad BK. Sliding wear behavior of bronze under varying material composition, microstructure and test conditions. Wear 2004;257:110-23.

[17] Equey S, Houriet A, Mischler S. Wear and frictional mechanisms of copper based bearing alloys. Wear 2011;273:9-16.

[18] Zeren A, Feyzullahoglu E, Zeren M. A study on tribological behavior of tin based bearing material in dry sliding. Mater Des 2007;28:318-23.

[19] Aksoy M, Kuzucu V, Turhan H. A note on the effect of phosphorus on the microstructure and, mechanical properties of leaded-tin bronze. J Mater Process Technol 2002;124:113-9.

[20] Kagohara Y, Takayanagi S, Haneda S, Fujita M, Iwai Yo. Tribological property of plain bearing with low frictional layer. Tribol Int 2009;42:1800-6.

[21] ELV Directive Adaptation to scientific and technical progress of Annex II Directive 2000/53/EC; 2007.

[22] Mukai R, Koyamas A, Hamaguchi N, Mouri K, Yokota H. Lead-free copperbased sintered (30) foreign application priority data sliding material and sliding parts. USA: Patent Application Publication; 2012.

[23] Zhao J, Qi L, Wang XM, Wang L. Influence of Bi on microstructures evolution and mechanical properties in $\mathrm{Sn}-\mathrm{Ag}-\mathrm{Cu}$ lead-free solder. J Alloy Compd 2004;375:196-201.

24] Saxton DM, Carpenter JM, Sevenski GW, Schmitt H, Andler G. Wear resistant lead free alloy bushing and method of making. USA: Patent Application Publication; 2008.

[25] HUANG ML, WANG L. Effects of $\mathrm{Cu}, \mathrm{Bi}$, and In on microstructure and tensile properties of $\mathrm{Sn}-\mathrm{Ag}-\mathrm{x} \quad(\mathrm{Cu}, \mathrm{Bi}, \mathrm{In})$ solders. Metall Mater Trans 2005;36A:1439-46.

[26] Kerr I, Priest M, Okamoto Y, Fujita M. Friction and wear performance of newly developed automotive bearing materials under boundary and mixed lubrication regimes. J Eng Tribol 2007;243:221-321.

[27] Ünlü BS, Atik E. Tribological properties of journal bearings manufactured from particle reinforced Al composites. Mater Des 2009;30:1381-5.

[28] Guo QB, Rong MZ, Jia GL, Lau KT, Zhang MQ. Sliding wear performance of nano- $\mathrm{SiO}_{2} /$ short carbon fiber/epoxy hybrid composites. Wear 2009;266:658-65.

[29] Li X, Cao Z, Zhang Z, Dang H. Surface-modification in situ of nano-SiO 2 and its structure and tribological properties. Appl Surf Sci 2006;252:7856-61.

[30] Sheng M, Wang Y, Zhong Q Wu H, Zhou Q Lin H. The effects of nano- $\mathrm{SiO}_{2}$ additive on the zinc phosphating of carbon steel. Surf Coat Technol 2011;205:3455-60.

[31] Zhang G, Chang L, Schlarb AK. The roles of nano- $\mathrm{SiO}_{2}$ particles on the tribological behavior of short carbon fiber reinforced PEEK. Compos Sci Technol 2009;69:1029-35.

[32] Sayuti M, Sarhan AAD, Salem F. Novel uses of $\mathrm{SiO}_{2}$ nano-lubrication system in hard turning process of hardened steel AISI4140 for less tool wear, surface roughness and oil consumption. J Clean Prod 2014;67:265-76.

[33] Sayuti M, Sarhan AD, Hamdi M. An investigation of optimum $\mathrm{SiO}_{2}$ nano lubrication parameters in end milling of aerospace Al6061-T6 alloy. Int J Adv Manuf Technol 2013;67(1-4):833-49.

[34] Jiao D, Zheng S, Wang Y, Guan R, Cao B. The tribological properties of alumina/ silica composite nanoparticles as lubricant additives. Appl Surf Sc 2011;257:5720-5.

[35] Peng DX, Kang Y, Hwang RM, Shyr SS, Chang YP. Tribological properties of diamond and $\mathrm{SiO}_{2}$ nano particles added in paraffin. Tribol Int 2009;42:911-7.

[36] Shang J, Ma W, Lu J. Formation of laminar structure under unlubricated friction of $\mathrm{Cu}-\mathrm{SiO}_{2}$ composite. Tribol Lett 2012;48:249-54. 
[37] Xiang Y, Zhang J, Jin C, Liu Y. Anti-friction properties of Cu10Sn-based composite containing nanometer diamond particles. Wear 2000;242:202-6.

[38] Sakai K, Zushi K, Sugita M, Ishikawa H. Development of a lead free copper based alloy for three layers bearings under higher engine loads. SAE World Congress, Detroit, Michigan, SAE 2004-01-1600; 2004.

[39] Bhushan B. Principles and applications of tribology. USA: Wiley; 1999.

[40] Lim CYH, Lim SC, Gupta M. Wear behavior of SiCp-reinforced magnesium matrix composites. Wear 2003;255:629-37.
[41] Technical Reference Manual, Wyko NT9300, Veeco Metrology Group, Tucson, Arizona, AZ85706.

[42] Morton RK. Topography of surface ASM Handbook—Surface Engineering 5; 1994 p. $136-138$.

[43] Song JF, Voburger TV. Surface texture ASM Handbook-Friction. Lubrication and Wear Technology 18; 1992 p. 334-345.

[44] Petropoulos GP, Pandazaras CN, Davim JP. Surface texture characterization and evaluation related to machining. Surf Integr Mach 2010. 